\title{
The Volta: A Galant Gesture of Culmination
}

\author{
NATHANIEL MITCHELL
}

\begin{abstract}
This article presents an overview of a new pre-cadential schema in the galant style: the Volta. The Volta is a two-part schema featuring a prominent chromatic reversal: stage one charges up the dominant with a $\sharp 4-\widehat{5}$ melodic string, while stage two releases to the tonic using a $\downarrow 4-\widehat{3}$ string. The schema sheds light on many aspects of galant music-making: its variants illustrate how central features of a schematic prototype motivate or constrain plausible manipulations, its pre-cadential function reveals the intimate communion between surface schemas and the harmonic patterns inscribed within the style's formal scripts, and, finally, its use as a climactic gesture in opera seria calls attention to the semantic possibilities of schemas beyond their role in defining musical topics. These and other aspects of the Volta are illustrated using representative excerpts from eighteenth-century masters like Leonardo Vinci, Giovanni Battista Pergolesi, Johann Adolf Hasse, Baldassare Galuppi, Joseph Haydn, and Wolfgang Amadeus Mozart.
\end{abstract}

Keywords: galant, schema, Cleofide, Hasse, Vinci, Pergolesi, abnegation, Koch, chromaticism, clausula, opera seria.

${ }^{6} \mathrm{~S}$ ancta mater, istud agas," the ninth movement of Giovanni Battista Pergolesi's Stabat Mater (1736), punctuates its predominantly tranquil affect with pockets of highly charged expressivity. The ritornello of this duet-shown in Example 1-begins with a light Romanesca, full of nimble triadic and scalar passagework, followed at m. 4 by a Prinner riposte embedded with the gently pulsating pedal-point sonorities and flatwise tonal inflections of the Quiescenza. ${ }^{1}$ The sixth measure then initiates a poignant expressive turn: the violins leap a tritone down from $\mathrm{Eb}$ to a sumptuous $A \npreceq$ enwrapped in a fully diminished-seventh chord, which discharges to the dominant $\mathrm{B} b$ in $\mathrm{m}$. 7. A rhyming gesture that accentuates $\mathrm{Ab}$ follows, highlighting a cross-relation between these two measures. The rhetorical energy of these measures-swelling sharpwise toward the dominant and then exhaling flatwise to the tonic-sets in motion the cadential progression that follows, after which the entirety of $\mathrm{mm}$. 68 is repeated to round off the opening ritornello.

Pergolesi treats this chromatic gesture as the movement's signature utterance; it is the only element from the opening ritornello to recur in every vocal period, acting in each instance as the phrase's penultimate, pre-cadential musical action. ${ }^{2}$ The

I owe a great debt to my many colleagues at Indiana University and Princeton University who have heard and commented upon numerous versions of this article. Special thanks to Scott Burnham, Kofi Agawu, Paul Sherrill, Hans Aerts, Poundie Burstein, Dmitri Tymoczko, and my two anonymous reviewers for their more extensive comments, critiques, and email discussions.

I The Romanesca, Prinner, and Quiescenza schemas are discussed in Chapters 2, 3, and 13, respectively of Gjerdingen (2007). Unless otherwise indicated, all schemas discussed in this article are defined in Gjerdingen (2007).

2 Subsequent presentations occur in mm. 18-23, 33-38, 51-54, 62-64, and 76-81. gesture likewise appears in a ritornello from the next duet"Inflammatus et accensus"; see Example 2-where it is condensed into a bare-octave presentation of the scale-degree string $\sharp \widehat{4}-\widehat{5}-\not \widehat{4}-\widehat{3}$ accompanied in the upper voices by the same "high $\widehat{1}$ " and "high $\widehat{2}$ " melodic prefixes seen in the "Sancta mater" duet. From these examples, we might abstract a conceptual prototype like the one shown in Example 3, following the example of Robert Gjerdingen in his 2007 monograph Music in the Galant Style. Gjerdingen posits that a core set of such formulaic prototypes-or schemas - underpins the compositional craft of eighteenth-century musicians, some of which (Romanesca, Prinner, and Quiescenza) have been mentioned already. The preceding examples suggest the existence of an additional item in the galant "schematicon"; ${ }^{3}$ a striking chromatic construction deployed as a powerful burst of energy preceding moments of cadential punctuation.

I call this schema by the Italian word for turn-voltahighlighting its opposition of a rising $\sharp \widehat{4}-\widehat{5}$ melodic string against a falling $\measuredangle \widehat{4}-3$ string. ${ }^{4}$ This article presents an overview of the Volta as a core schema in the galant style, with special emphasis on its use in opera. I begin by refining the schematic representation offered above with an enriched pool of exemplars, probing the common range of contrapuntal and rhythmic variations that composers deployed when using this

3 Rice (2015a).

$4 \mathrm{I}$ intend the name Volta to call up incidental semantic associations as well. For instance, one might connect the Volta's pre-cadential function to the poetic volta of the Shakespearean sonnet, a turn toward the sonnet's concluding idea often ushered in through clauses like "and yet" or "but" that signal a pointed discursive shift. For a discussion of the poetic volta as an essential feature of sonnet rhetoric, see Bermann (1988, especially pp. $45 \mathrm{ff}$. and 84). One might also associate the term with the SI unit for electromagnetic force- the volt, named after the eighteenth-century physicist Alessandro Volta — to highlight the schema's high energy, its "electricity." 

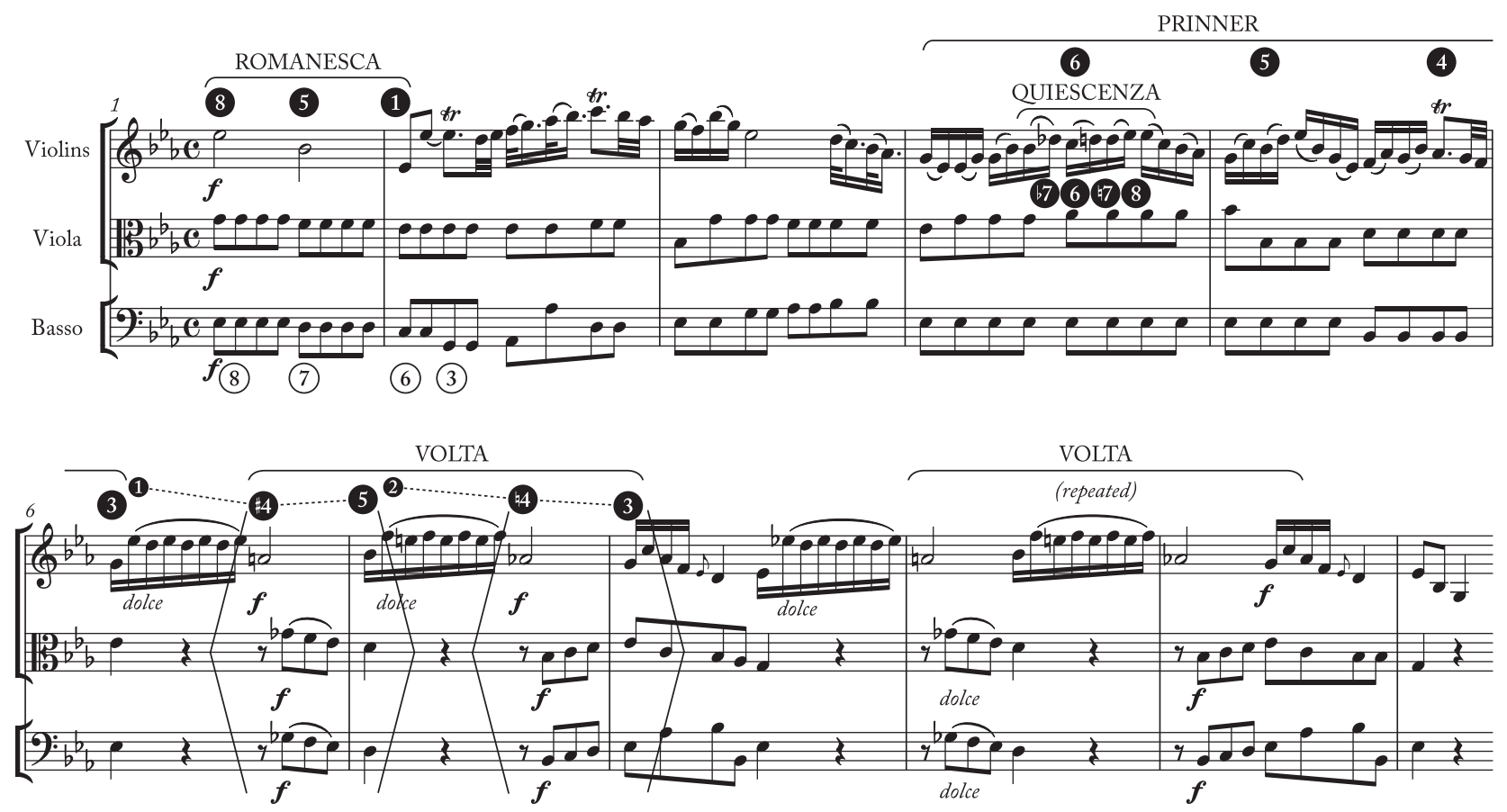

example r. Giovanni Battista Pergolesi, Stabat Mater (1736), LX. "Sancta mater istud agas," mm. 1-11

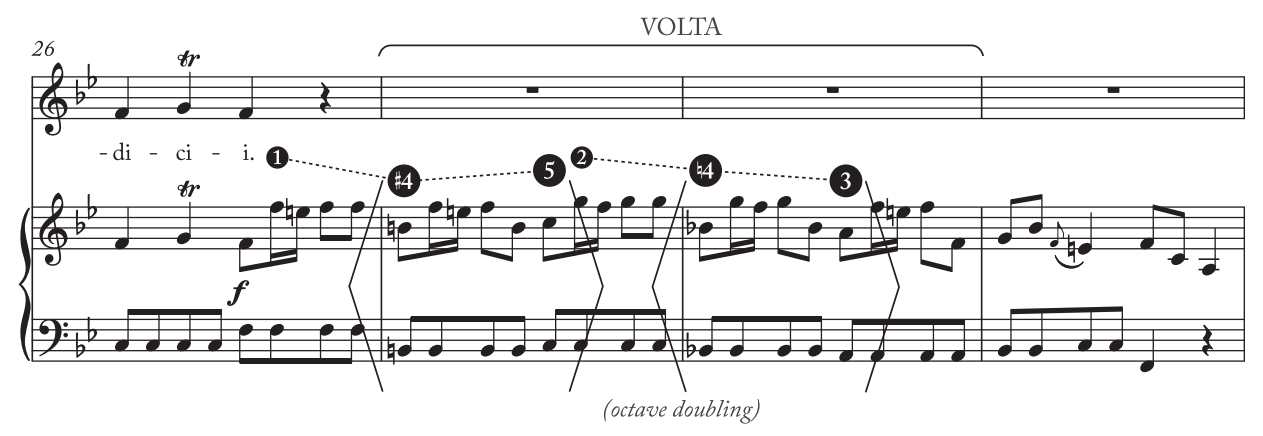

EXample 2. Pergolesi, Stabat Mater, XI. "Inflammatus et accensus," mm. 26-29

schema. A primary concern of this section will be to connect the schema's variants to the prototypical features that motivate them, thereby tracing paths from the schema's inner core to ambiguous boundary areas where musical phenomena share features with multiple prototypes. ${ }^{5}$ Once the structural features of the Volta have been secured, I then explore the schema's syntactical and expressive associations. Its pre-cadential function opens a window onto the cross-pollination of foreground contrapuntal constructions with scripted event sequences at broader scales of musical time. Its rhetorical role as a marker of musical climax, on the other hand, encourages sensitive

5 As George Lakoff (1987) uses the term, motivation pertains to cognitive phenomena that are neither fully predictable nor wholly arbitrary. Motivation provides an account for why certain category applications, instances of polysemy, extensions of metaphors or idioms, etc. make sense while others do not, an explanation that works by describing how the elements of a conceptual system fit together to facilitate sense-making.

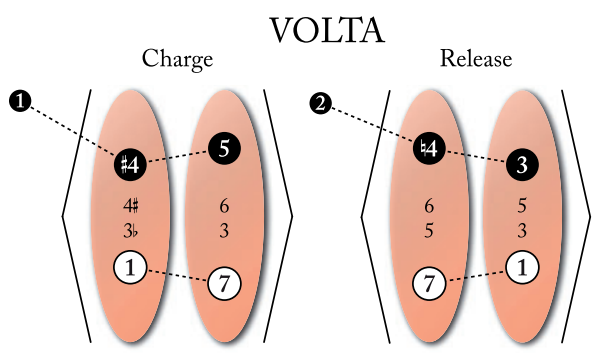

EXAMPLE 3. The Volta, conceptual prototype

engagement with the narrative potential of musical schemas, especially in operatic contexts. Thus, this article not only contributes an item to the growing schematicon of eighteenthcentury music, but also uses that schema to reflect on issues of schematic definition, manipulation, and combination, as well as temporal and expressive signification in the galant style. 


\section{DOUBLE-CLAUSULA PROTOTYPE AND BASIC EXTENSIONS}

On 13 September 1731, the Dresden court of August the Strong inaugurated a new era of musical prosperity with the premiere of Johann Adolf Hasse's heroic opera Cleofide. ${ }^{6}$ Hasse, as the Elector of Saxony's newly hired maestro di cappella, was the evening's star attraction, it being the first public occasion for the court to witness the artistic fruit procured by their investment in the young composer. With Cleofide, then, Hasse had to demonstrate his supreme mastery of the most fashionable and dramatically evocative musical devices of the day in service of a magnificent performance that could testify to the state's renewed artistic prowess. His unparalleled success in this regard cemented his lucrative position and launched a golden age of operatic production for Dresden that would last, with Hasse at the helm, until Frederick the Great invaded Saxony in 1756, igniting the cataclysmic events of the Seven Years' War.

Hasse was especially renowned for his delectably sweet melodies and for his ability to spotlight vocal expression with impeccably clear orchestral textures. ${ }^{7}$ These talents are on full display in the aria that opens Cleofide's third act, where Gandarte pines in vain for the love of fair Erissena with the following delicate verses:
Pupillette-vezzosette
De l'amato mio tesoro:
Non vi basta dir ch'io moro.
Mi negate ancor pietà.
Tutto amor voi m'accendete, E pur siete-tanto ingrate;
Che un diletto ogn'or vi fate
De la vostra crudeltà.

within this largely diatonic palette, perhaps employing the schema's chromatic rise and fall to evoke the inhalation and exhalation of an expressive sigh. The Volta's special affective status is already evident in the passage from the opening ritornello shown in Example 4(a), where, following a series of sparse unisono cadences, the fully voiced chromatic schema crackles to life in a climactic moment of amorous expression. This orchestral skeleton is further enriched when the Volta returns in the vocal period. In the passage shown in Example 4(b), Gandarte plugs his upbeat-oriented vocal gestures into the orchestra's rhythmic gaps and further adds an ascending grace note into the downbeat of $\mathrm{m}$. 67, thereby amplifying the schema's affective poignancy with a twinge of accented dissonance. The result is a delicately constructed pas de deux between singer and orchestra that masterfully coordinates audience attention: the schema's accented chromaticism leaps out of its diatonic surroundings to draw focus to the stage, after which the orchestra recedes to give Gandarte's expressive semitonal sighs full, unencumbered sway over the hearts of an enraptured audience.

Hasse, who early in his career acquired the sobriquet "il Sassone," surely represented an ideal candidate for the Dresden court-here was a native German composer with a firm mastery of the Italian style refined as a pupil of the great Neapolitan maestro Alessandro Scarlatti. ${ }^{9}$ Early on in his apprenticeship, Hasse, like countless other budding composers on the Italian peninsula, would have acquired great fluency with the tritone-resolving, $\mathrm{V}^{7}-\mathrm{I}$ punctuation formulas shown in Example 5. ${ }^{10}$ Once mastered, these clausulas served as a foundational resource for the generation of longer, more elaborate patterns. The Volta, for instance, can be viewed as a clausula altizans $\left(\mathrm{V}_{2}^{4}-\mathrm{I}^{6}\right)$ to the dominant followed by a clausula cantizans $\left(\mathrm{V}_{5}^{6}-\mathrm{I}\right)$ to the tonic. ${ }^{11}$ The Volta was one of several gestures constructed in this way: as shown in Example 6, it

Hasse clothes Gandarte's love song in the flirtatious trappings of a ${ }_{8}^{6}$ forlana, upon which he develops a kaleidoscopic texture layered with playful points of imitation, simple homophony with motion in parallel thirds, unadorned unisono passages, and so on. ${ }^{8}$ Like Pergolesi in the Stabat Mater, Hasse adds the Volta as a delicate splash of chromatic color

6 On the historical circumstances surrounding the premiere of Cleofide, see Millner (1976), Strohm (1988), and Heartz (2003).

7 Sweetness and textural clarity are central, for instance, in the following appraisal by Charles Burney $(1773,235)$, "The merit of Signor Hasse has so long, and so universally been established on the continent, that I have never yet conversed with a single professor on the subject, who has not allowed him to be the most natural, elegant, and judicious composer of vocal music ... equally a friend to poetry and to the voice, he discovers as much judgment as genius, in expressing words, as well as in accompanying those sweet and tender melodies, which he gives to the singer. Always regarding the voice, as the first object of attention in a theatre, he never suffocates it ... but is as careful of preserving its importance, as a painter, of throwing the strongest light upon the capital figure of his piece."

8 On the characteristics of the forlana and its association with courtship, see Heartz (1999) as well as Little and Jenne (2009). Heartz identifies a characteristic "forlana cadence" with a $\widehat{5}-\widehat{6}-\widehat{7}-\hat{1}$ melody, a variant of which may be seen in m. 19 of Ex. 4(a).

9 Millner (1976) has shown that early German critics like Mizler and Scheibe viewed Hasse as an ideal German composer, proof of the superiority of German musicianship.

Io On the stylistic importance of clausulas in general, see Gjerdingen (2007, the partimenti of Alessandro Scarlatti, see Ciolfi (2011).

II I choose to represent the Volta prototype, in addition to being extremely common, as an altizans $\rightarrow$ cantizans pair for three conceptual reasons: first, the prototype adheres to Gilad Rabinovitch's $(2018,66)$ principle that "in most schema types containing the 4-7 tritone, its members are situated in the perceptually salient outer voices"; second, when the schema's tritone components are situated in the outer voices, the outer voices attain the smoothest possible voice leading; and, third, the prototype gives the schema's characteristic chromaticism to the highest voice. This last preference rule, which privileges an altizans $\rightarrow$ cantizans prototype over the closely related cantizans $\rightarrow$ altizans alternative, may be a consequence of the reportorial focus of my corpus. That is, opera's vocal theatricality may impose the constraint that exciting and attention-grabbing chromaticism should typically be given to the singer, a constraint that might not be felt in instrumental or non-theatrical genres. 139ff.) as well as Rabinovitch (2018). For a discussion of clausulas within 
(a)

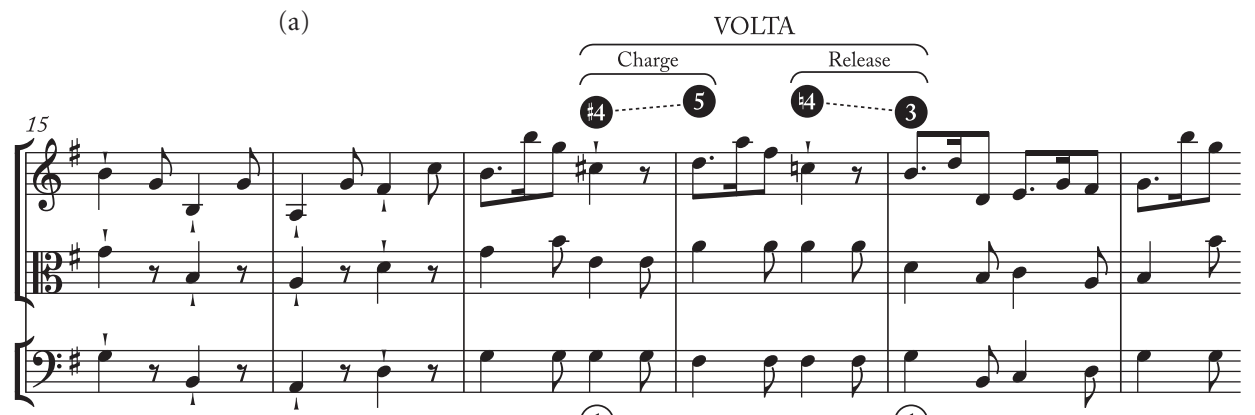

(1) (7)....... (7)

(7)

(1)

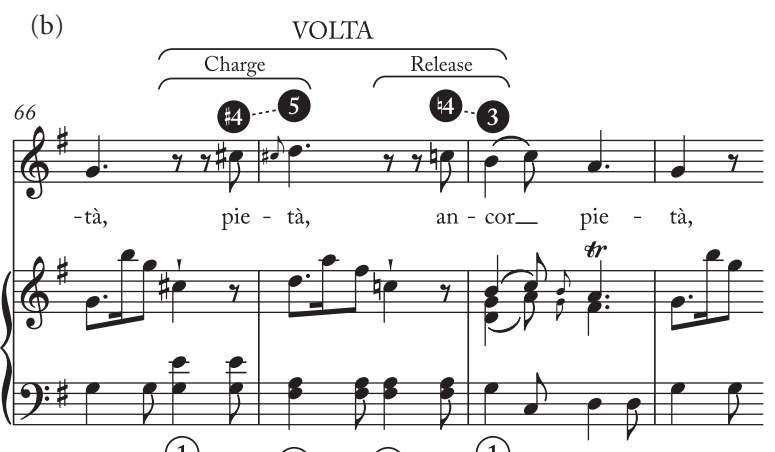

(1).

(7)

(7)

(1)

example 4. Johann Adolf Hasse, Cleofide (1731), Act III, Scene 1, "Pupillette vezzosette." (a) mm. 15-20. (b) mm. 66-69

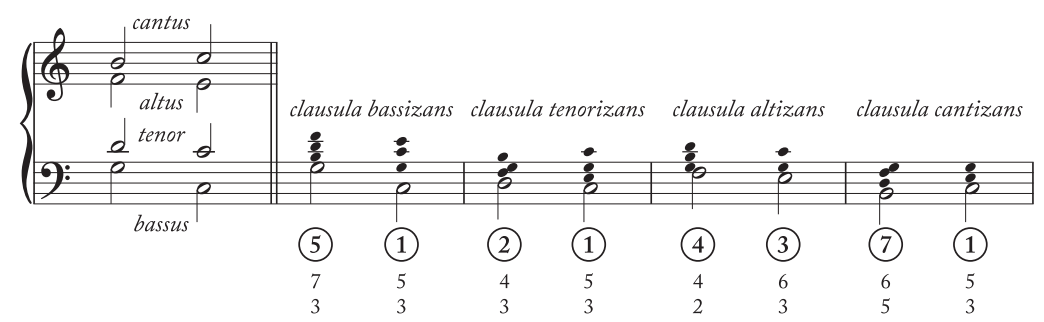

EXAMPLE 5. Derivation of four basic clausulas from a four-voice prototype
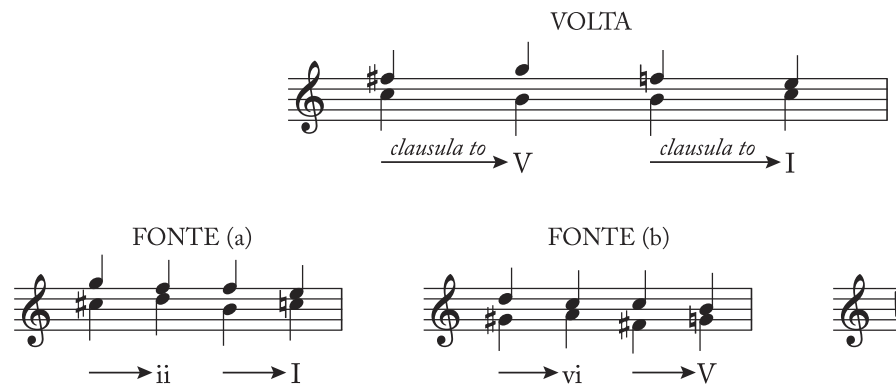

MONTE
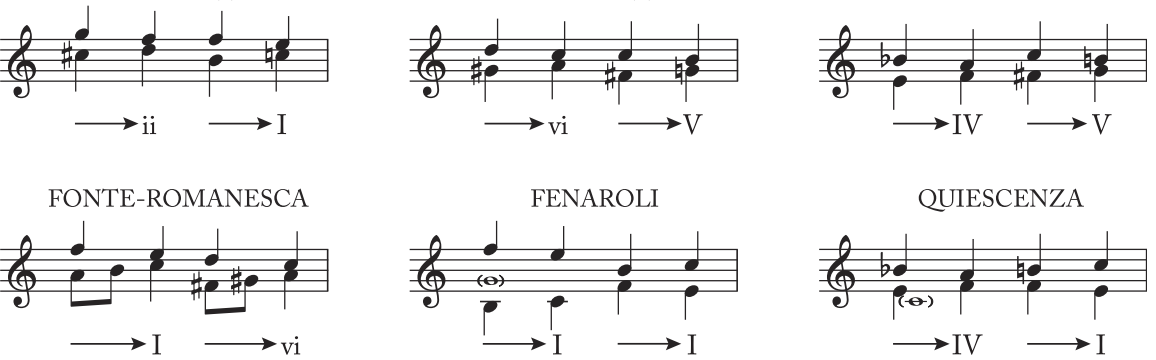

EXAMPLE 6. The Volta and the double-clausula family 


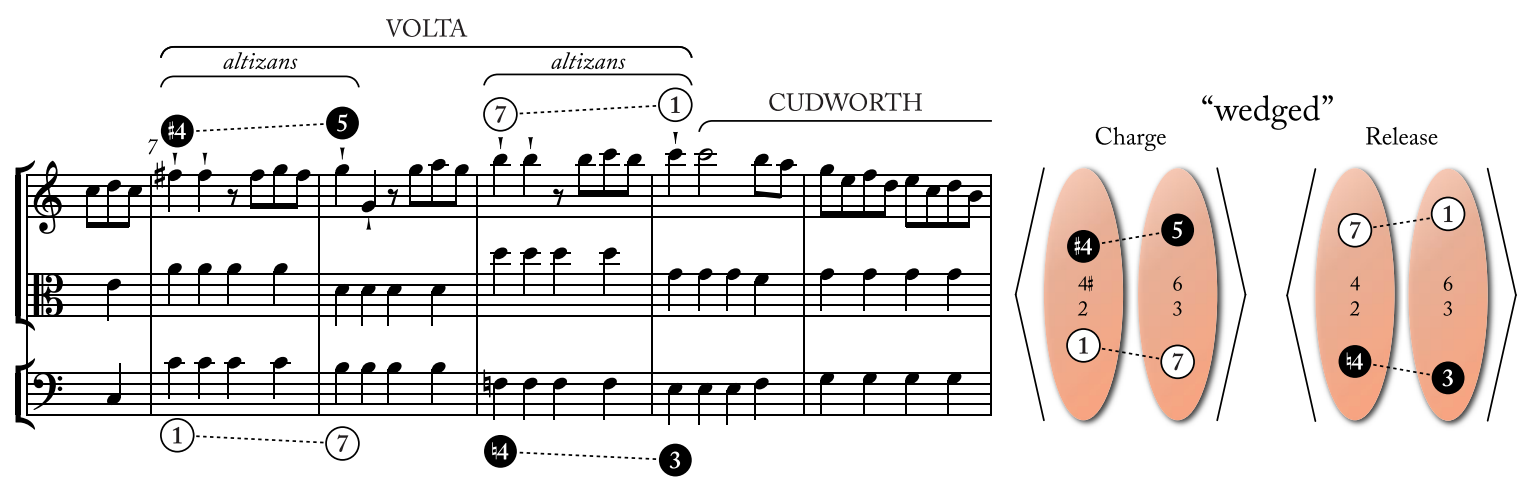

example 7. Hasse, Cleofide, Act II, Scene 12, "S'è ver che t'accendi," mm. 7-11

forms a family of "double-clausula" schemas along with sequential patterns like the Fonte, Monte, and FonteRomanesca, as well as additional schemas like the Fenaroli and the Quiescenza. ${ }^{12}$ By situating the Volta within this network, we highlight important points of contact with other core schemas in the style: its dominant charge stage might remind one of the end of a Monte, its sense of "departure-return" is quite close in effect to the Fonte, and it is a mirror image of Quiescenza both harmonically (feinting first to the dominant rather than the subdominant) and melodically $(\sharp \widehat{4}-\widehat{5}-\measuredangle \widehat{4}-\widehat{3}$ mirroring the Quiescenza's $b \widehat{7}-\widehat{6}-\curvearrowleft \widehat{7}-\widehat{1})$. Thus, clausulas and their attendant tritone resolutions act as the style's "atomic units" (to borrow Gilad Rabinovitch's characterization), connecting individual gestures into organized networks and thereby enabling what schema theorists, following Leonard Ratner, have called the style's ars combinatoria - the art of generating rich compositions through creative combinations of simple schematic materials. ${ }^{13}$

Clausulas are particularly useful for this "art of combinations" because they are fully invertible. This imbues the members of the double-clausula family with a special property: their melodic strings can always appear in the bass without producing an ungrammatical musical effect. ${ }^{14}$ Hasse takes advantage of this feature in another aria from Cleofide, Alessandro's "S'e ver che t'accendi" from Act II. As shown in

I2 Unlike the other members of the double-clausula family, Vasili Byros's (2017) Fonte-Romanesca schema is prototypically constructed out of two "long clausulas" featuring $\widehat{6}-\widehat{7}-\hat{1}$ bass strings.

I3 Rabinovitch $(2018,64)$ discusses multi-clausula schemas, a discussion that touches briefly on the Volta. On the eighteenth-century ars combinatoria, see Ratner (1970), as well as Gjerdingen (2007) and Berkowitz (2010) for more recent applications to schema theory.

I4 A schema like the Romanesca, on the other hand, has a characteristic $\widehat{1}-\widehat{5}$ $-\widehat{1}-\hat{1}$ melodic string that generates an ungrammatical I-V-vi ${ }^{6}-\mathrm{I}$ harmonic succession when transferred to the bass. While, as we will see below, not all clausula combinations are equally common, it is nevertheless true that any schema constructed entirely out of clausulas can always be inverted without yielding an untenable harmonic succession on the musical surface.
Example 7, the opening ritornello features an energetic "wedged" variant of the Volta created by swapping the characteristic soprano and bass strings for the schema's second stage. $^{15}$ As a result, the "inhale/exhale" effect of the alti$z a n s \rightarrow$ cantizans prototype is replaced by an altizans $\rightarrow$ altizans profile that forcefully wedges outward. Through this simple act of clausula substitution-Klauselverwechslung in the North German Klausellehre tradition-Hasse has adapted the Volta's harmonic core to a new melodic impulse, sending the violins rocketing up to a climactic high point and setting up a tumbling series of octave-descending Cudworth cadences to close out the ritornello. ${ }^{16}$ This example illustrates that the structural properties of a schematic prototype motivate specific paths for varying that schema-that is, because the members of the double-clausula family are constructed out of fully invertible components, we might expect clausula substitution to play a central role in generating variants of those schemas. ${ }^{17}$

Clausula substitution can also bring a schema into contact with other important style structures. Example 8 shows a Volta from the opera's opening number, the eponymous Queen Cleofide's "Che sorte crudele." Melodically, this Volta is identical to the one just seen in "S'e ver che t'accendi" (and once again leads to a Cudworth cadence), but now, the soprano's $\sharp 4-\widehat{5}-\widehat{7}-\widehat{1}$ string is matched to a melodically fluent

I5 In this and all remaining examples, scale-degree annotations in black circles express segments of the schema's prototypical soprano string $(\sharp \widehat{4}-\widehat{5}-\downarrow \widehat{4}-\widehat{3})$ regardless of where in the texture that string occurs.

I6 See Neuwirth $(2015,123)$ for a discussion of Klauselverwechslung in the theoretical works of North German theorists like Andreas Werckmeister.

I7 It seems to be the case that double-clausula prototypes composed of two identical clausulas, such as the cantizans $\rightarrow$ cantizans Monte and Fonte schemas, do not typically have significant clausula-altering variants. Thus, one would expect bassizans $\rightarrow$ bassizans or altizans $\rightarrow$ altizans variants for these schemas, but would not expect, say, cantizans $\rightarrow$ altizans variants to be common. This suggests that schemas with clausula-preserving prototypes are not easily extended to clausula-altering configurations, likely because uniform transposition is integral to their sequential identity. In other words, sequential double-clausula schemas can be thought of as a subfamily characterized by an additional feature in their prototype (that their component clausulas are related by uniform transposition), and this feature in turn provides additional constraints on clausula substitution. 


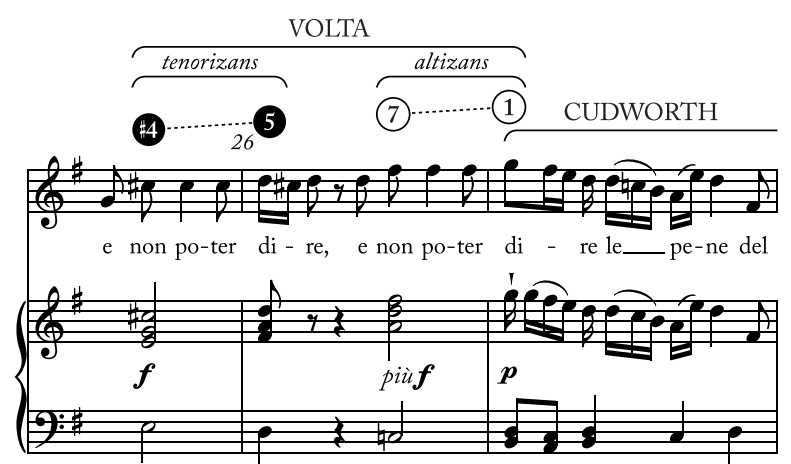

(6)………(5) (4) 3

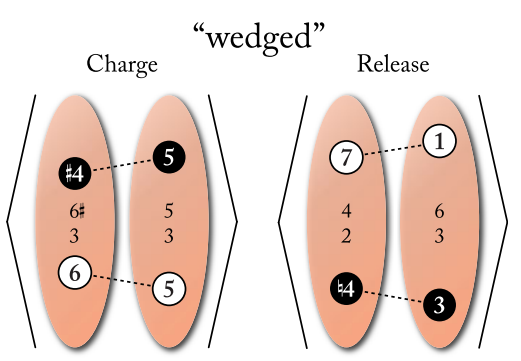

Rule of the Octave bass

example 8. Hasse, Cleofide, Act I, Scene 2, “Che sorte crudele," mm. 25-27

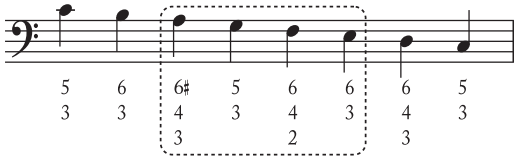

EXAMPLE 9. The Volta as a tetrachordal subset of the descending Rule of the Octave

$\widehat{6}-\widehat{5}-\widehat{4}-\widehat{3}$ string in the bass, yielding a tenorizans $\rightarrow$ altizans clausula profile. Notably, the harmony/bass profile of this variant is identical to a segment of the Rule of the Octave, a foundational pedagogical tool in the eighteenth century for deriving implied harmonies from a stepwise bass. As shown in Example 9, Cleofide's Volta matches the central tetrachord of the standard descending Rule of the Octave, a tetrachord that brings chromatic emphasis to the dominant as a local point of stability before passing down to $\widehat{3} .^{18}$ The Volta thus joins the Prinner and the Modulating Prinner as schemas generated from tetrachordal subsets of the Rule of the Octave, thereby taking advantage of a central opposition between tonic and dominant embedded within the style's chief abstraction of tonal propriety.

Hasse acquired the fame necessary to procure his position at the Dresden court through a half-decade of success on the Neapolitan and Venetian operatic circuits, where he put his training into action in a deeply competitive commercial environment. The most notable of Hasse's professional rivals in this formative period was the Neapolitan master Leonardo Vinci, whose operas are likewise replete with exemplary Voltas. Features from each of the Cleofide examples discussed so far may be found, for instance, in the excerpt from Vinci's Artaserse shown in Example 10: the Volta's characteristic $\sharp \widehat{4}-\widehat{5}-\downarrow \widehat{4}-\widehat{3}$ melodic string appears unbroken in the singing voice as in "Pupillette vezzosette," the upper strings are

I8 The Rule of the Octave is discussed extensively Gjerdingen (2007) and in scholarship that follows from his work, especially Sanguinetti (2012), van Tour (2015), and Rabinovitch (2018). arranged in a wedge formation reminiscent of "S'è ver che t'accendi" (vln. 1 taking $\widehat{1}-\widehat{7}-\widehat{4}-\widehat{3}$ and vln. 2 taking $\sharp \widehat{4}-\widehat{5}-\widehat{7}-\widehat{1})$, and this melodic complex is supported by an altizans $\rightarrow$ bassizans clausula pair, illustrating an instance of clausula substitution that preserves the schema's prototypical soprano string. Vinci's musical practice thus resonates deeply with that of his rival Hasse, and equally so with the young Pergolesi, who may have studied with Vinci at the Conservatorio dei Poveri di Gesù Cristo in Naples. ${ }^{19}$

Vinci, Hasse, and Pergolesi were the three most powerful compositional voices of the emerging galant style; their operas were consumed across Europe and fast became a primary benchmark for musical excellence. Charles Burney, for instance, singled out these three composers as compositional paragons with a long line of "successors, who pursuing the track which Vinci, Hasse, and Pergolesi had first traced out, have advanced into new regions of invention, taste, grace, elegance, and grand effects." 20 By attending to the way that these three composers deployed and manipulated the Volta schema, we not only deepen our musical understanding of this nascent period of galant opera, but also pinpoint compositional models for later generations of composers. To get at the dissemination of this model, as well as the full range of contrapuntal options made possible by clausula substitution, Example 11 provides an at-a-glance, bite-sized history of the Volta using paradigmatic excerpts from each decade between 1720 and the century's end. These excerpts simultaneously exhaust the possibilities for clausula substitutions while also highlighting other minor variants, like the stage-one augmented sixth in Example 11(a), the mixture of fully voiced and unisono textures in Examples 11(b) and 11(d), and the inner-voice presentation

I9 Charles Burney $(1789,552)$ remarks that "the instant [Pergolesi] quitted the conservatorio, he totally changed his style, and adopted that of Vinci, of whom he received lessons in vocal composition." For further discussion, see Markstrom (2007, 256-57).

20 Burney $(1789,356)$. 


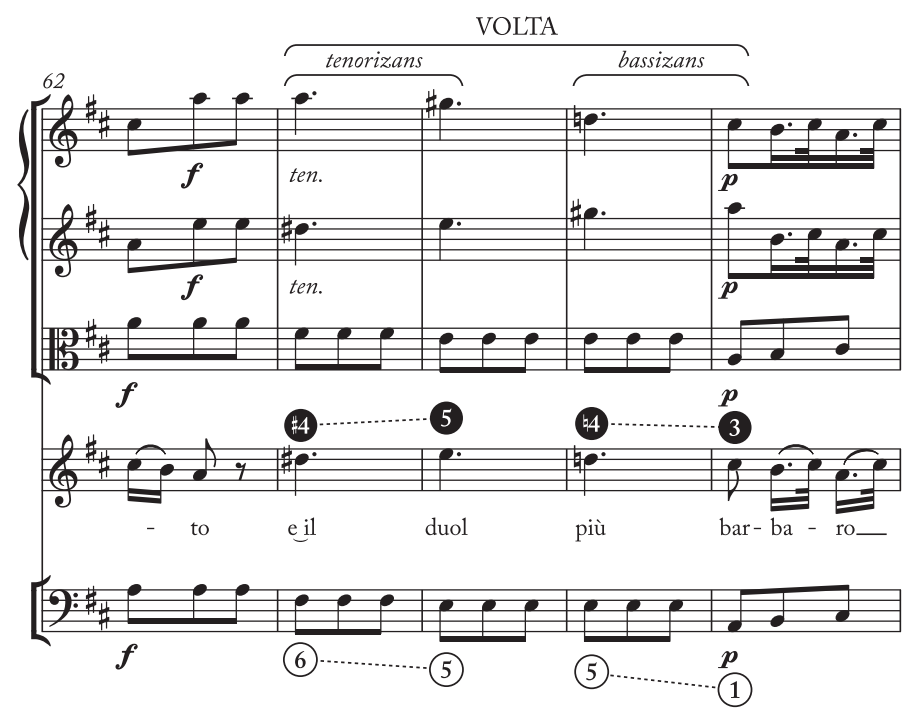

eXAmple io. Leonardo Vinci, Artaserse (1730), Act I, Scene 7, "Bramar di perdere," mm. 62-66

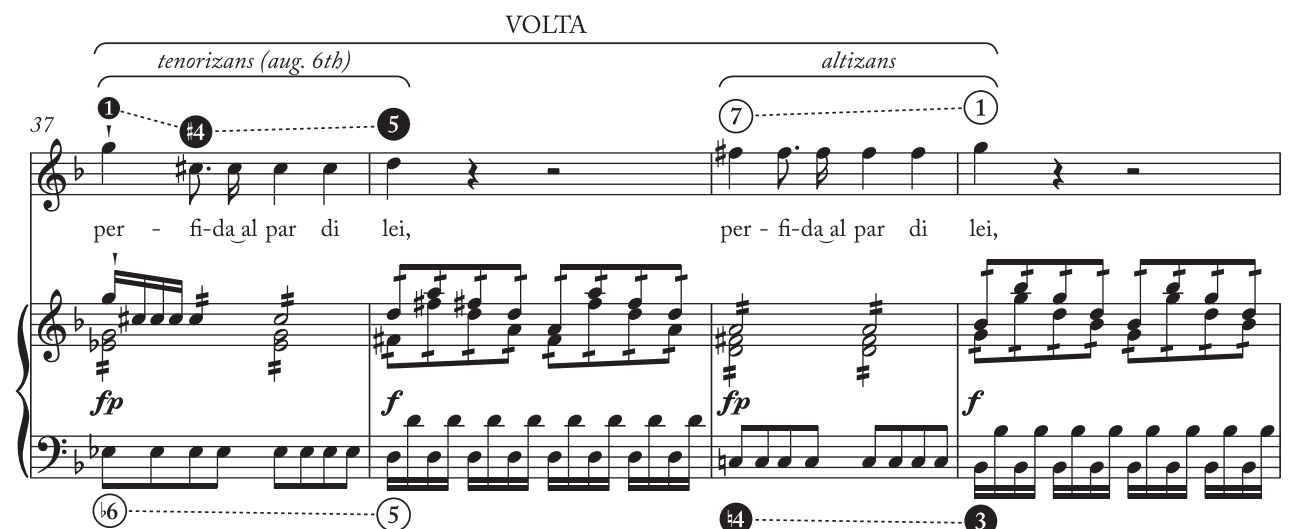

EXAmple ir. Paradigmatic Voltas by decade, 1729-1790. (a) Vinci, Catone in Utica (1729), Act II, Scene 13, "Dovea svenarti allora," mm. 37-40

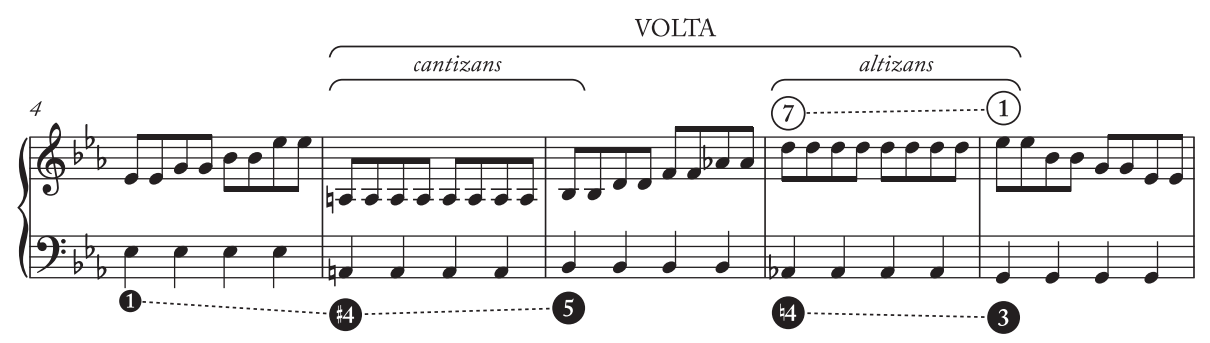

eXample ir(b). Pergolesi, La serva padrona (1733), Act II, Scene 3, "Son imbrogliato io giá," mm. 4-8 


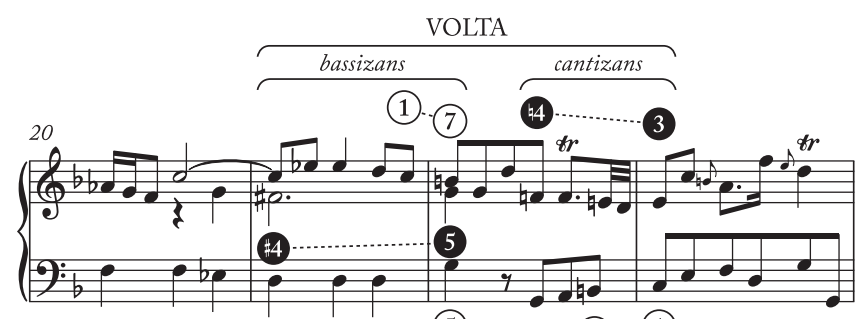

(2).

(5)

(7)....(1)

example ir(c). Carl Philipp Emanuel Bach, Sonata in F major, Wq. 48, no. 1, first movement, mm. 20-23

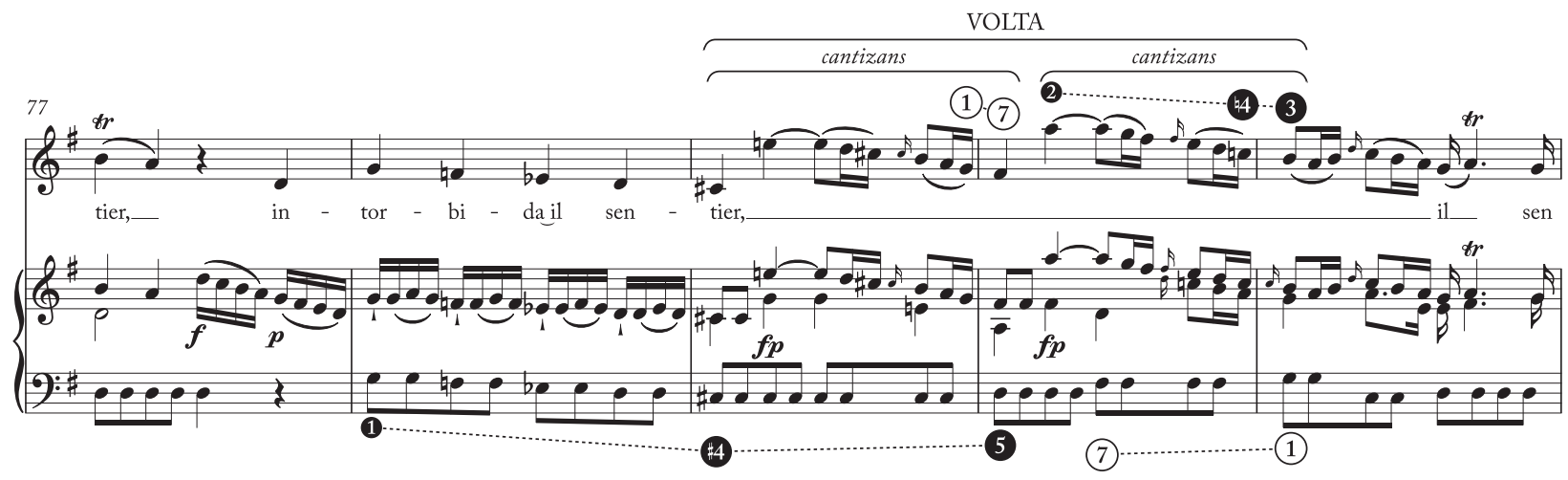

example ir(d). Giovanni Battista Ferrandini, Catone in Utica (1753), Act II, Scene 5, “Soffre talor del vento," mm. 77-81

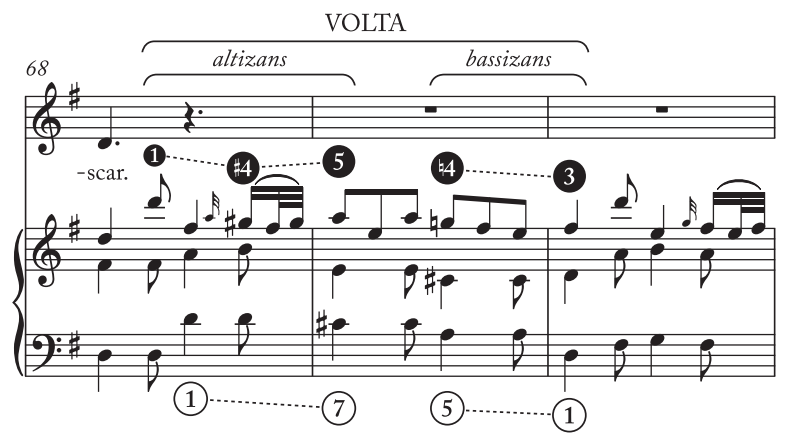

eXAmple ir(e). Baldassare Galuppi, L'amante di tutte (1760), Act II, Scene 4, “Conoscerete un giorno,” mm. 68-70

of tritone atoms in Examples $11(\mathrm{c})$ and $11(\mathrm{~g}) .^{21}$ The survey also reveals certain asymmetries in the construction of the two stages; for instance, while stage one may take any clausula, the 2-1 tenorizans clausula is not generally available for stage two,

2I The only remaining grammatical combination not labeled in these examples is the bassizans $\rightarrow$ bassizans pair. However, Ex. 11(c) could be regarded as a bassizans $\rightarrow$ bassizans Volta whose stage-two bass string is filled in with a characteristic stepwise diminution pattern also seen in Exs. 1, 11(f), and 26. For a "pure" example of a bassizans $\rightarrow$ bassizans Volta, see mm. 35-36 of Ex. 32. perhaps owing to the general rarity of the clausula vera in this style. $^{22}$ Finally, Example 11(f) illustrates a more distant variant in which the Volta's two stages map onto a rising Long Comma bass $(\widehat{6}-\widehat{7}-\widehat{7}-\widehat{1})$ rather than onto two component "short" clausulas, a variant we will return to below.

22 Rabinovitch $(2018,71)$. Another apparently ungrammatical clausula combination is the $\widehat{2}-\widehat{5}-\widehat{4}-\widehat{3}$ bassizans $\rightarrow$ altizans pair. The bassizans clausula is thus the only clausula that, if used in stage one, constrains the possibilities for stage two: the only grammatical pairs are bassizans $\rightarrow$ bassizans $(\widehat{2}-\widehat{5}-\widehat{5}-\widehat{1})$ and bassizans $\rightarrow$ cantizans $(\widehat{2}-\widehat{5}-\widehat{7}-\widehat{1})$. 


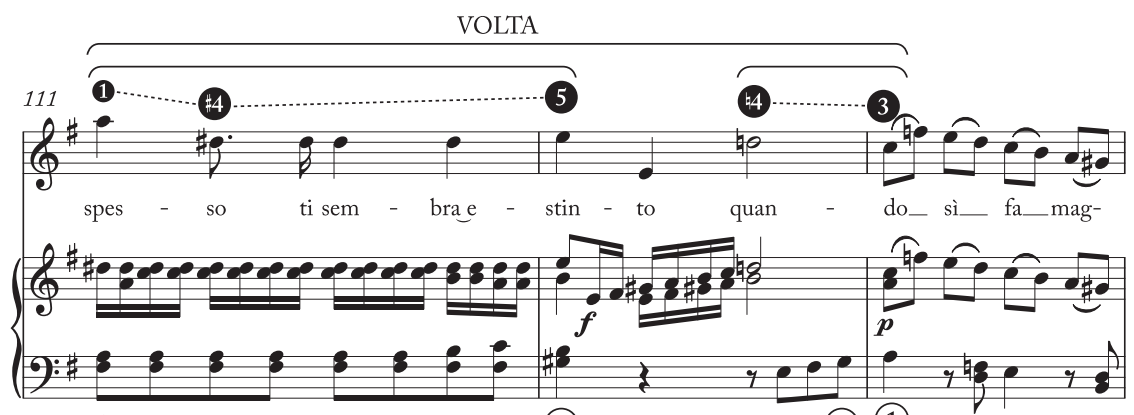

(6).

(7)

(7). (1)

LONG COMMA

eXample ir(f). Hasse, Ruggiero (1771), Act II, Scene 6, "Lo sdegno ancor che fiero," mm. 111-13

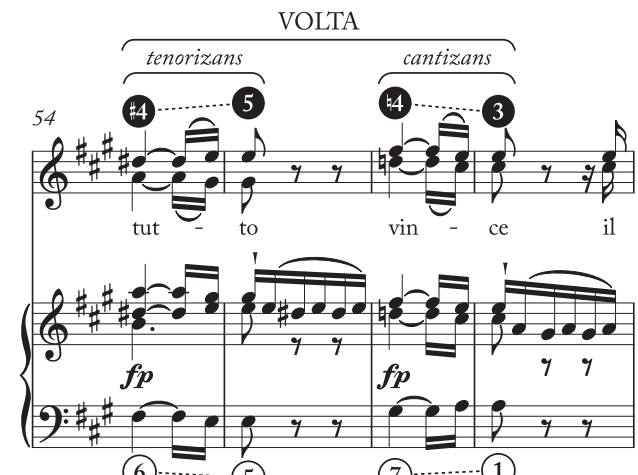

(6) $=(5)$

(7).........(1)

eXample iI(g). Mozart, Idomeneo, K. 366, Act III, Scene 2, "S'qio non moro a questi accenti," mm. 54-57

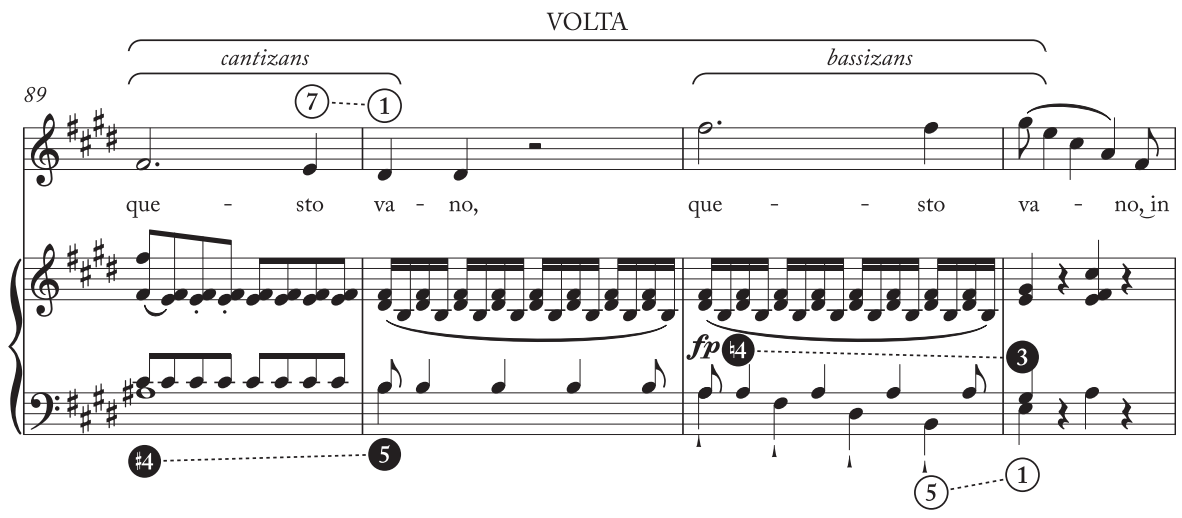

example ir(h). Mozart, Cosí fan tutte, K. 588, Act II, Scene 7, “Per pietá, ben mio, perdona,” mm. 89-92

In light of these excerpts, Example 12 presents an elaborated conceptual prototype for the Volta schema. This revised model captures the schema's most common contrapuntal variants by expanding the number of characteristic bass lines associated with each stage and highlighting the potential for an exchange of paradigmatic melodic strings between the schema's opening and closing stages. Because these variations are motivated by the inherent invertibility of clausulas, we can think of Example 12 as making explicit contrapuntal possibilities that are already implicit in the original prototype, extensions that a skilled composer might elaborate automatically after internalizing one of the schema's core exemplars. The two examples might thus be thought to model two different phases in a hypothetical learning process, with Example 3 


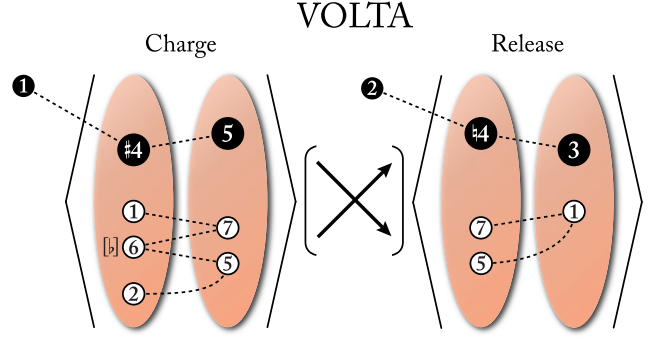

EXAMPLE I2. The Volta, elaborated conceptual prototype

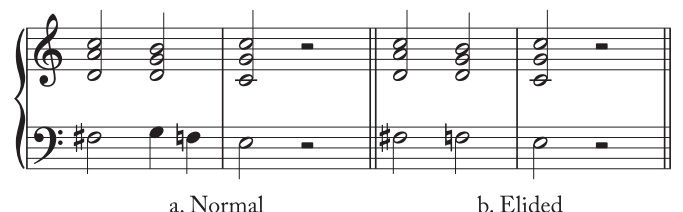

EXAMPLE i3. Resolutions of $V_{5}^{6} / V$ to $V_{2}^{4}$

capturing what a studious young musician might take from a famous exemplar like Pergolesi's Stabat Mater, and Example 12 illustrating a phase of mastery in which the prototype interfaces with broad networks of musical knowledge, facilitating creative elaborations and flexible applications.

\section{ABNEGATION AND TRUNCATION}

Robert Hatten draws attention to our schema as a case study in hermeneutic interpretation in his 1994 monograph Musical Meaning in Beethoven. Focusing on the progression's paired presentation of upward "yearning" and downward "yielding" impulses, Hatten explores the expressive implications of eliding out $\widehat{5}$ from its core melodic string, as shown in Example 13. Example 14 reproduces Hatten's core example of this expressive elision-taken from the second movement of Beethoven's Piano Sonata in Eb Major, Op. 7-to which I have added labels identifying the presence of galant schemas. ${ }^{23}$ By eliding out $\widehat{5}$, Beethoven juxtaposes the upward impulse of the schema's opening "charge" stage directly against the downward impulse of its "release" stage without providing $\sharp \widehat{4}$ with a

23 Hatten $(1994,58)$. The changing-note schema was initially discussed by Meyer (1973) with reference to its $\widehat{1}-\widehat{7}-\widehat{4}-\widehat{3}$ melodic form. The category was subsequently broadened to include other melodic strings amenable to I-V-V-I harmonic progressions in Meyer and Rosner ([1982] 2000, 166) and Gjerdingen (1988, 55-59), many of which (but not the $\widehat{3}-\widehat{4}-\widehat{2}-\widehat{3}$ variant) were then individually named in Gjerdingen (2007). Unlike Mirka (2014, 369-70), I do not frame the $\widehat{3}-\widehat{4}-\widehat{2}-3$ changing note schema as a retrograde member of the $\widehat{3}-\widehat{2}-\widehat{4}$ $-\widehat{3}$ Pastorella category, since so doing obscures the fine melodic distinctions that prompted Gjerdindgen to individuate various changing-note schemas in the first place. In lieu of its own distinctive category, I prefer to return the $\widehat{3}-\widehat{4}-\widehat{2}-\widehat{3}$ melodic type to its parent category of I-V-V-I changing-note schemas, while recognizing the potential for future research to tell the individual story of the $\widehat{3}-4-\widehat{2}-$ 3 schema. proper melodic resolution, suggesting a powerful and expressively potent redirection of $\sharp 4$ 's energy. For Hatten, this elevates the yielding impulse of the gesture's closing stage from passive to purposeful action, signifying the Romantic cultural unit of "abnegation," or "willed resignation and spiritual acceptance of a (tragic) situation that leads to a positive inner state, implying transcendence." 24

Although Hatten's example seems quite distant from the works we have examined so far, his derivation process suggests an additional line of variation within the Volta category based on rhythmic truncation of the schema's two-part, four-event prototype. This "Volta tronca" subgroup is likewise motivated by harmonic repetition across the boundaries of the schema's two stages, a feature that allows the prototype's four-event structure $(\mathrm{X}-\mathrm{Y} \mid \mathrm{Y}-\mathrm{Z})$ to be compressed into three events (X$\mathrm{Y}-\mathrm{Z}){ }^{25}$ One variant in this group-illustrated in the passage from Cleofide shown in Example 15-truncates the harmonic dimension only, preserving the schema's fourfold melodic string $(\sharp \widehat{4}-\widehat{5}-\curvearrowleft \widehat{4}-\widehat{3})$ by expressing $\widehat{5}-\natural \widehat{4}$ as $6-5$ (or $8-7$ ) motion

24 Hatten $(1994,287)$. Abnegation must be understood as an expressive category that may be correlated with various musical phenomena, not as merely another name for the Volta schema. Hatten himself traced the process by which Beethoven, over the course of the second movement of Op. 7 , abstracted abnegation from its initial presentation as a truncated Volta and realized the expressive category using other harmonic events, maintaining only the juxtaposition of the original pitch classes $\mathrm{F} \sharp$ and $F$. Frank Samarotto (2004) has likewise explored the expressive potential of $\sharp \widehat{4} / \measuredangle \widehat{4}$ juxtapositions in examples ranging from Gottfried Stölzel to Claude Debussy, further detaching the expressive shade of this chromatic juxtaposition from the specific eighteenth-century practices that shaped the Volta schema. Finally, Vasili Byros (2014) has explored how a very different musical event, the modulation to $G$ minor at the beginning of Beethoven's "Eroica" Symphony, likewise participates in a larger narrative that communicates abnegation, illustrating that expressive categories may attach onto a wide variety of musical events. On the one hand, these cases demonstrate the difference between an expressive category, which is a cultural signified that may be called up by diverse signifiers, and the kind of contrapuntal schema that forms the heart of Gjerdingen's project, which, like a topic (Hatten 1994, 81), is a relatively stable correlation of signifying musical devices with signified syntactical and expressive functions. On the other hand, if the Volta as a contrapuntal schema is hypothesized as an early vehicle for the expression of abnegation, as Hatten and Samarotto's examples suggest, then the abstraction of abnegation from its parent schematic category supports a central stylistic claim of schema theory expressed by Meyer $(1989,245-46)$ and Gjerdingen $(1988,266)$ : the scripted and stereotyped schematic lexicon characteristic of the eighteenth century provided a core set of resources for the more abstract and plan-based narrative strategies characteristic of nineteenth-century music.

25 Within the double-clausula family, harmonic repetition is a unique property of the Volta schema. However, this feature is exceedingly common in what Rawbone and Jan (2015) call "butterfly schemas": four-event schemas grouped into rhyming pairs that express the harmonic structure "I-departure [to V] | return [from V]-I." This class includes many schemas that serve presentational functions within the galant style, such as the Meyer schema and its changing-note cousins, as well as the four-part versions of the Sol-Fa-Mi and the Do-Re-Mi. While not all butterfly schemas have corresponding three-part variants, the Sol-Fa-Mi and the Do-Re-Mi do, which suggests that the Volta's harmonic affinity to these schemas motivates shared variation paths. 


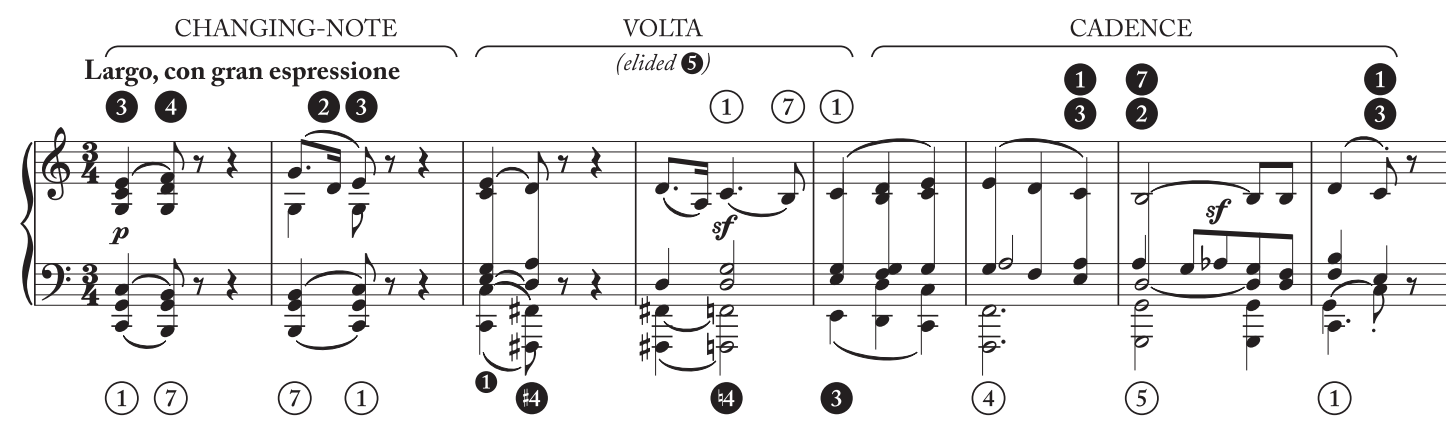

EXAmple 14. Beethoven, Sonata in Eb Major, Op. 7, second movement, mm. 1-8
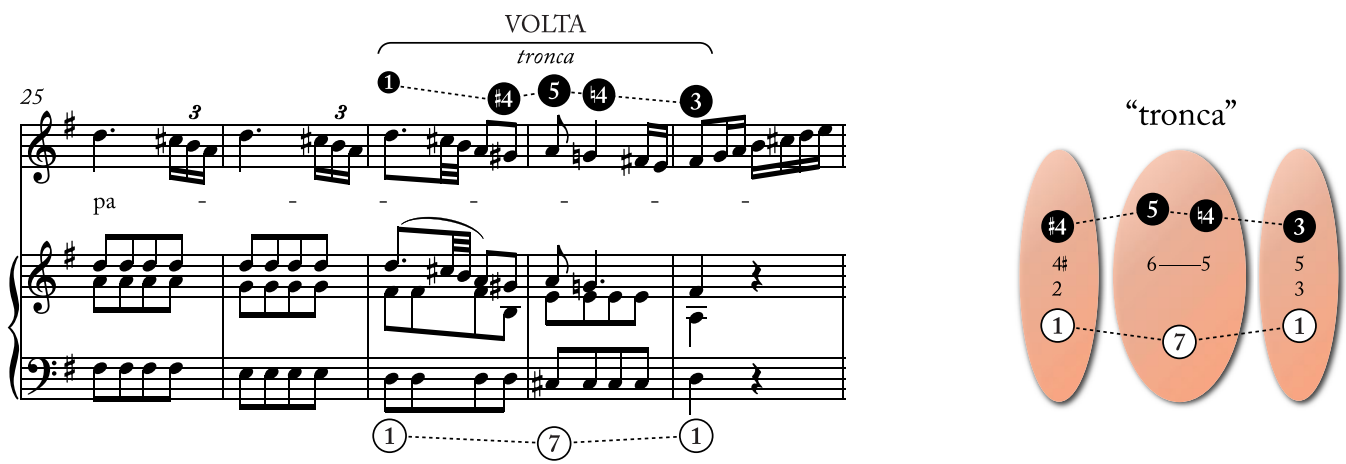

example i5. Hasse, Cleofide, Act I, Scene 8, “Se mai turbo il tuo riposo," mm. 25-29
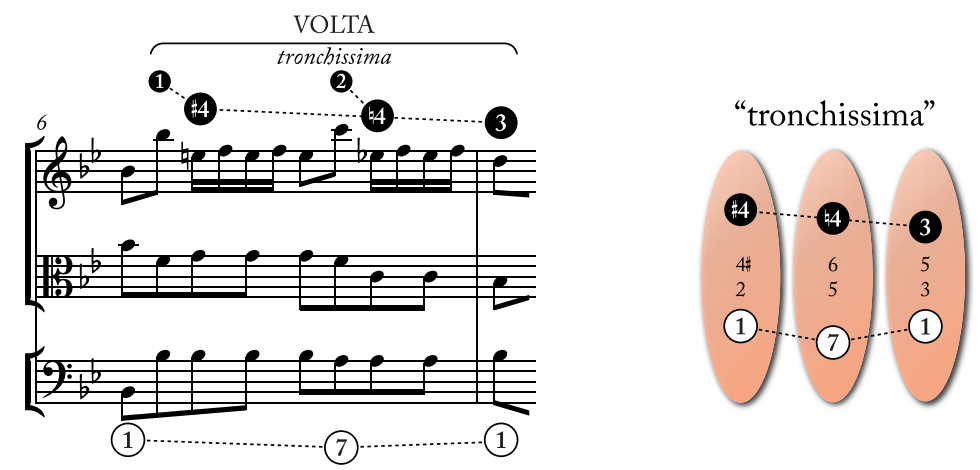

eXample i6. Vinci, Didone abbandonata (1726), Act I, Scene 19, "Se resto sul lido," mm. 6-7

over a single dominant harmony. A second, more distant variant is shown in Example 16 and features both harmonic and melodic elision $-\widehat{5}$ is expelled entirely from the schema, producing a threefold $\sharp \widehat{4}-\measuredangle \widehat{4}-\widehat{3}$ melodic string. Notably, both examples are prototypical in most other respects-including their use of characteristic diminution patterns like high 1 (Examples 15 and 16) and high $\widehat{2}$ (Examples 16 only) melodic prefixes-which secures their aural resemblance to the prototype even in the absence of core rhythmic or melodic elements.

Thus, two distinct features of the Volta prototype motivate two distinct paths for variation: the schema's double-clausula structure motivates contrapuntal variants via clausula substitution and its cross-stage harmonic repetition motivates rhythmic variants via elision. Such transformations, alone or in tandem, press prototypes into new shapes that are adaptable to a variety of compositional purposes, such as the expression of abnegation or the construction of passages with loose-knit phrase rhythms. ${ }^{26}$ But they also drive individual examples away from a schema's prototypical core and toward the category's edges. Most of the examples we have seen so far are clearly and directly related to the prototype; one need only shuffle the voices or perform a simple rhythmic expansion to

26 On tight-knit vs. loose-knit phrase structure, see Caplin (2000). 


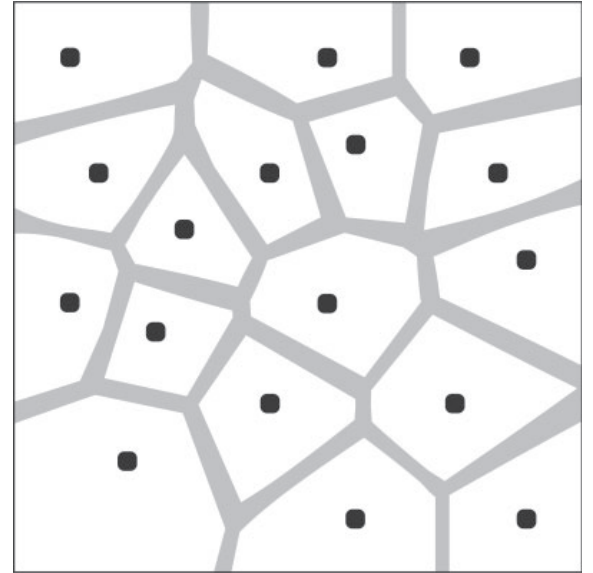

EXAMPLE I7. Conceptual space for graded categories

be right back to our original model from the Stabat Mater duet. But with a case like Beethoven's Op. 7, a good deal of effort is required to connect foreground pitch configurations back to the prototype, such that if we hear the Volta schema at all in Beethoven's theme (as Hatten's model suggests that we should) it may be in part because no other schematic model gets us any closer. ${ }^{27}$ In the next section, I turn to phenomena that exist in the liminal space between the Volta and other familiar schemas, and which are hence genuinely ambiguous. Doing so helps to establish a sense of the category's cognitive limits while offering a glimpse of the many musical possibilities that may be constructed with reference to multiple basic prototypes.

\section{AT THE BOUNDARIES: VOLTAIC SCHEMAS}

To hear a musical schema is to relate an experienced phenomenon to similar experiences, situating the musical event within a network of comparable structures. Categories based on experiential similarity, like colors and musical schemas, tend to be graded with respect to both centrality and membership, meaning some instances of the category are better examples than others, and membership in the category is a matter of degree. Example 17-adapted from Lieven Decock and Igor Douvenprovides a simple visualization for the conceptual space of graded categories as a two-dimensional collated Voronoi diagram. ${ }^{28}$ In

27 A feature like the $\widehat{1}-\sharp \widehat{4}$ bass leap in m. 4 does call to mind one of Volta's characteristic foreground diminutions, but there are also many confounding features, like the delayed appearance of a melodic $\widehat{1}$ until the second beat of m. 5 (after $\sharp \widehat{4}$ has moved to $\measuredangle \widehat{4}$ ), and the rather un-Volta-like grouping structure, which suggests a two-stage, four-event butterfly schema moving $I-V_{5}^{6} / \mathrm{V} \mid V_{2}^{4}-I^{6}$. A more convincing instance of a Volta tronca in Beethoven (actually a "Voltaic Long Comma," see the next section) may be found in $\mathrm{mm}$. 468-75 of the first movement of the "Pastoral" Symphony, Op. 68.

28 A Voronoi diagram divides a metric space into cells such that each cell has a central point and contains all and only those points that lie no closer to the center of any other cell as they do to the center of their own cell. this representation, the central black region of each cell represents a category's conceptual prototype, the surrounding white region includes the clear members of a category that exhibit varying degrees of atypicality, and finally the grey regions form areas of graded membership where phenomena relate to multiple prototypes. Given that galant musicians delighted in combining and manipulating the rich materials of their musical language, we should expect to encounter various hybrid phenomena constructed out of characteristic features from several schemasphenomena that skirt the grey areas of Example $17 .{ }^{29}$

In the $1770 \mathrm{~s}$, one popular gesture combined the Volta's characteristic chromatic opposition with an ascending $\widehat{6}-\widehat{7}-\widehat{1}$ bass, what Gjerdingen has called the Long Comma. To get a sense of the wealth of options made possible by such a combination, Example 18 walks a path from Long Comma to Volta, drawing examples from Haydn's symphonic output from this period. In its prototypical form, the Long Comma features an ascending $\widehat{6}-\widehat{7}-\widehat{1}$ bass paired with a $\widehat{4}-\widehat{3}$ melody (see Example 18[a]), and like the Volta often prepares a stronger cadential articulation to follow. ${ }^{30}$ When the Long Comma proceeds from an octave sonority on $\widehat{5}$, the descending soprano string may be enriched with a chromatic passing tone to yield a $\widehat{5}-\sharp \widehat{4}-\downarrow \widehat{4}-\widehat{3}$ string, as in Example 18(b). A composer might

Voronoi diagrams are useful for representing categories with graded centrality, but not graded membership, since only points that are precisely equidistant from two centers can be construed as categorically unclear or vague. By first acknowledging that conceptual prototypes represent a circumscribed range of features within a category rather than one unique reference point (Rosch 1978), multiple Voronoi diagrams may be generated from the individual points that make up the prototypical range. Projecting these individual Voronoi diagrams onto one another produces a collated Voronoi diagram, which has "thick" edges and is thus useful for modeling categories with graded membership. This procedure is summarized in Decock and Douven (2014), condensing the more extended formulation in Douven et al. (2013).

29 Gjerdingen (2007), Rice (2017), and Byros (2017), for instance, have explored several Romanesca hybrids, though their discussions often emphasize the distinct usage histories that grant these hybrids an individual cognitive status as well as a corresponding degree of stability and permanence within the style. This is especially true of the Monte-Romanesca, which Gjerdingen $(2007,99)$ indicates "could equally well be treated as a separate schema," and which Rice (2017) describes as "neither a Monte nor a Romanesca but a schema with its own long history and its own set of expressive connotations." Other ambiguous phenomena, such as William Caplin's (2000) hybrid phrase types, have a more contingent and unstable existence: individual examples might tip toward one model or another depending on the particular constellation of features evident in the piece, but stable new prototypes seldom emerge through this process. In other words, some of the boundaries of Example 17 are entrenched and resistant to change, while others can be reshaped in a flash with the appearance of a new prototype.

30 As Gjerdingen $(2007,157)$ and Byros $(2013,236)$ point out, clausulas, especially cantizans and altizans clausulas, are often called upon to secure the tonic prior to a cadential progression, a point discussed further in relation to Heinrich Koch's conception of galant form below. The Volta might be thought of as a chromatically "charged" take on pre-cadential clausulas. 
(a)

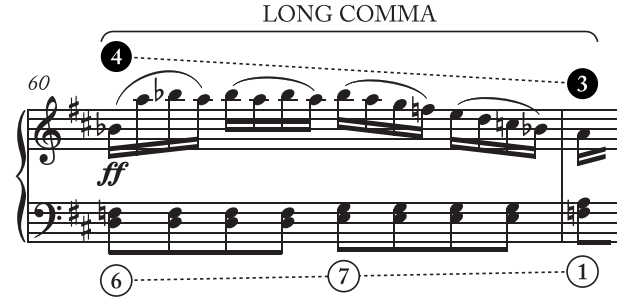

(b)

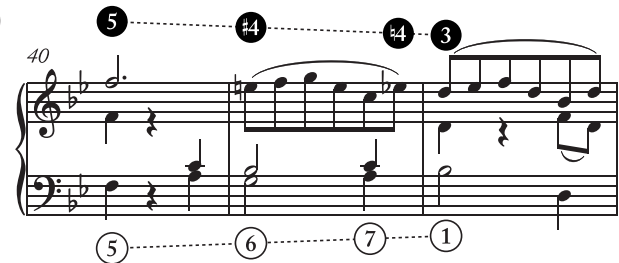

(c)

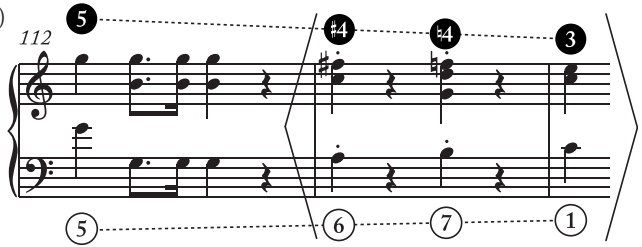

(d)

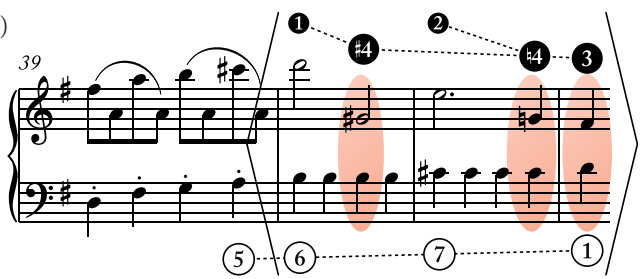

(e)

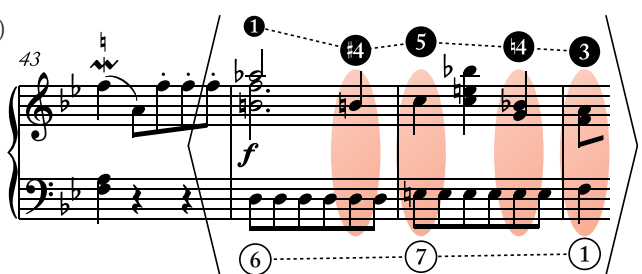

(f)

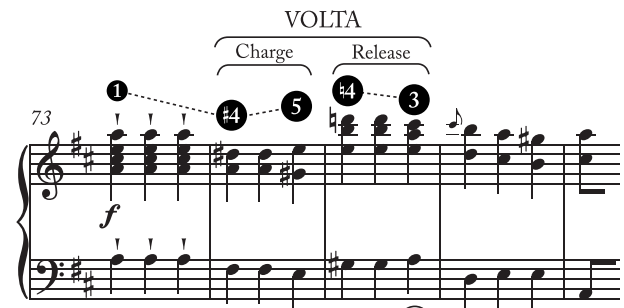

(6).

(5) (7) (1)

eXAMPle 18. (a) Haydn, Symphony No. 73 in D Major, first movement, mm. 60-61. (b) Haydn, Symphony No. 66 in BD

Major, third movement, mm. 40-42. (c) Haydn, Symphony No.

56 in C Major, fourth movement, mm. 112-14. (d) Haydn,

Symphony No. 54 in G Major, first movement, mm. 39-42. (e)

Haydn, Symphony No. 68 in Bb Major, first movement, mm.

43-46. (f) Haydn, Symphony No. 70 in D Major, first movement, mm. 73-77 then highlight the $\sharp \widehat{4}$-to- $\llbracket \widehat{4}$ chromatic succession through dynamic emphasis or textural isolation, as shown in Example 18(c), thus emphasizing the chromatic juxtaposition for its own sake. The Volta's shade is brought into sharper focus once $\sharp \widehat{4}$ and $\sharp \widehat{4}$ acquire their characteristic high $\widehat{1}$ and high $\widehat{2}$ melodic prefixes, as in Example 18(d). The $\sharp 4$ might then release some of its energy by touching briefly on $\widehat{5}$ before proceeding onto $\sharp \widehat{4}$, producing a Volta tronca like the one shown in Example 18(e). Resolving the bass $\widehat{6}$ down to $\widehat{5}$ finally severs the link to the Long Comma, yielding a rhyming two-part Volta in an altizans $\rightarrow$ cantizans configuration, shown in Example 18(f). Thus, reading Example 18 from start to finish, Long Comma typicality declines as Volta typicality rises, and vice-versa. This gradual shift from one prototypical pole to the other likewise correlates with an energetic mutation of $\sharp \widehat{4}-$ from a downward-inflected chromatic passing tone between $\widehat{5}$ and $\widehat{4}$, to a leading tone that is drawn upward to $\widehat{5}$-with examples in the middle of the continuum exploring an abnegation-like redirection of scale-degree energy.

What facilitates the conceptual overlap between Volta and Long Comma is the Rule of the Octave-this time in its ascending form - which acts as a "genus" organizing multiple "species" of musical schemas. Example 19 reproduces the various options for harmonizing an ascending scale given by Carl Philipp Emanuel Bach in the second part of his Versuch über die wahre Art das Clavier zu spielen, which provide "the briefest and most natural means of which a keyboardist, particularly one of limited ability, may avail himself in extemporizing."31 With this pedagogical goal in mind, Bach proceeds from the simplest scale harmonizations (variants $\mathrm{a}$ and $\mathrm{b}$ ), through various sequential patterns (c, d, and e), before arriving finally at rich options for harmonic figuration suffused with artful diminutions. Focusing on the harmonization of the bass string $\widehat{6}-\widehat{7}-\widehat{8}$, we can see that half of the figuration patterns (shaded on the figure) set an upper voice $\sharp \widehat{4}$ against $\sharp \widehat{4}$, most of which are clustered toward the more artful end of Bach's presentation. (Note especially variant $h$, the only one in which $\sharp \widehat{4}$ resolves to $\widehat{5}$ before descending to $\measuredangle \widehat{4}$.) This suggests that the ascending Rule of the Octave could generate the diatonic Long Comma as a high-level default (a, c, and d), a paradigmatic Volta as a very low-level default (h), and various $\sharp \widehat{4}-\not \widehat{4}-\widehat{3}$ melodic descents in between ( $\mathrm{b}, \mathrm{f}$, and $\mathrm{g})$.

The Long Comma and the Volta, then, are conceptual frames that resonate with a wide variety of musical phenomena, phenomena that may call out to features from both categories. This relationship is facilitated in turn by the musical forces captured by the Rule of the Octave as an abstract tonal schema. What the examples on the border between Volta and Long Comma share is a play on the chromatic opposition of $\sharp \widehat{4}$ and $\sharp \widehat{4}$. The potency of this cross relation can call to mind the expressive and rhetorical force of the Volta even in the absence of some of its more characteristic melodic devices. As such, it can be helpful to identify such distant kinship by

3I $\operatorname{Bach}([1753 / 1762] 1949,432)$. 


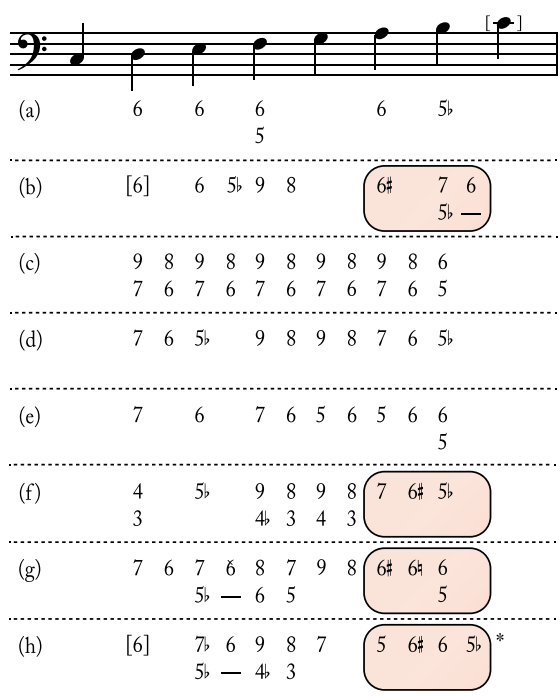

EXAMPLE I9. Figures for the harmonization of an ascending major scale

using adjectival forms of schema names: in this case, the "Voltaic" Long Comma. ${ }^{32}$ Though it might be objected that such a naming scheme multiplies the terminology in an analytical discipline already plagued by excessive neologism, it encourages more honest engagement with the vicissitudes of schematic perception, which may occasion sudden flashes of recognition based on only fleeting associations - a momentary whiff of a strangely familiar scent. ${ }^{33}$

With this, we complete our tour of the Volta's characteristic harmonic and rhythmic structure. Beginning with a basic fourpart, double-clausula prototype, we have explored various ways that the prototype may be manipulated and extended to account for less prototypical configurations. Those extensions were motivated by broader style structures-such as clausula substitutions, harmonic elision, and the various chromatic affordances of the Rule of the Octave-each of which constrain plausible ways of manipulating the prototype. But the Volta is more than just an amalgam of pitches and rhythms: like all schemas, its structure is inexorably bound to its use and meaning. ${ }^{34}$ In the case of the Volta, those meanings have both form-functional and rhetorical dimensions; the schema typically serves a pre-cadential formal function, and performs the

32 Such a naming convention might also be extended to, for instance, "Quiescent" schemas: describing gestures that are infused with the Quiescenza's characteristic $b \widehat{7}$ chromatic shade (cf. mm. 58ff. of "Ah perdona al primo affetto" from Mozart's La clemenza di Tito for a "Quiescent Romanesca").

33 Here, I adapt Kofi Agawu's (2014, 475) metaphor for a similarly flexible approach to topic theory. He writes, "A texture may suggest a topic without stating it explicitly; listeners may catch only a whiff of a particular topic... Topical analysis requires a gradation of reference and a sensitive set of discovery procedures that will render topics as shadows in dim light rather than fully visible bodies, allusions rather than presences, or conversations overheard rather than heard."

34 On schemas as form-meaning pairs, see Gjerdingen and Bourne (2015). rhetorical function of bringing a phrase's kinetic energy to a climax before the relative comforts of stock cadential schemas. For the remainder of this article, I attend to these characteristic features of the Volta's use, tying the schema's pre-cadential function to $\sharp \widehat{4}-\widehat{5}-\downarrow \widehat{4}-\widehat{3}$ paradigms commonly found in the pre-cadential zones of galant formal scripts and exploring the schema's dramatic function within opera seria. ${ }^{35}$

\section{HALF CADENCES AND THE VOLTA'S PRE-CADENTIAL FUNCTION}

Because of its V-I, double-clausula structure, the Volta bears a strong family resemblance to any schematic collocation that leads with a dominant-concluding schema and responds with a tonic-concluding schema. Examples 20 and 21 illustrate how the dominant-ending chromatic wedge progression that John Rice has called the Morte can pair with various clausulas in ways that either amplify or suppress the conceptual overlap between such a pairing and the Volta. ${ }^{36}$ Example 20, from Andrea Bernasconi's L'Olimpiade, emphasizes the half-cadence effect at the end of the Morte by repeating its augmentedsixth conclusion, which in turn frames the clausula altizans that follows as a new beginning. Example 21, returning us once again to Hasse's Cleofide, links its three schematic subunits together through rhyming melodic figurations, drawing this passage close to the Volta's conceptual prototype. ${ }^{37}$ These examples speak to the subtle distinction between a Volta on the one hand, and an $\mathrm{HC}$ effect that is followed by a return to tonic on the other. Since the Volta is a perceptual gestalt

35 Scripts are schemas for the temporal shape of routinely experienced events The concept was originally developed by Schank and Abelson (1977) subsequently used to characterize musical schemas by Gjerdingen (1988), and applied to large-scale musical structure by Meyer (1989) and Byros (2015).

36 Rice (2015b).

37 A similar situation occurs in Ex. 11(h), in which mm. 89-90 serve to both conclude a preceding Indugio schema (not shown; mm. 84ff.) and to open a Volta, with a shift in texture (among other hypermetrical and motivic considerations) marking $\mathrm{m} .89$ as a new beginning rather than as a simple continuation of the preceding measures. Also related to this is the situation where a dominant-oriented schema performs the Volta's opening stage. This happens, for instance, in Ex. 11(d), where the opening charge stage may be characterized as an unisono presentation of Vasili Byros's (2009) Le-Sol-Fi-Sol schema. Indeed, several of Byros's Le-Sol-Fi-Sol examples continue onto tonic-oriented clausulas in ways that suggest a larger Volta schema (cf. ibid., 255 for an example from Haydn's Symphony No. 96). This relationship is especially pertinent to the Volta's characteristic Quintabsatz $\rightarrow$ Schlußsatz formal function discussed below, since Byros (2015, 235) describes the Le-Sol-Fi-Sol as an "anchor point" for the end of a dominant Quintabsatz. It should be noted that, to paraphrase Gjerdingen and Bourne (2015, "Usage-Based Knowledge"), "schema theory is neutral as to whether" such phenomena are properly described as "(1) one construction with two or more component schemata, (2) two constructions collocated as a higher-level prefab, or (3) two or more constructions used in a stereotypical pattern of discourse." That is, we can say that the Volta is entangled with Le-Sol-Fi-Sol $\rightarrow$ clausula collocations, but we do not at present have a way of determining the conceptual primacy of one representation against another. 


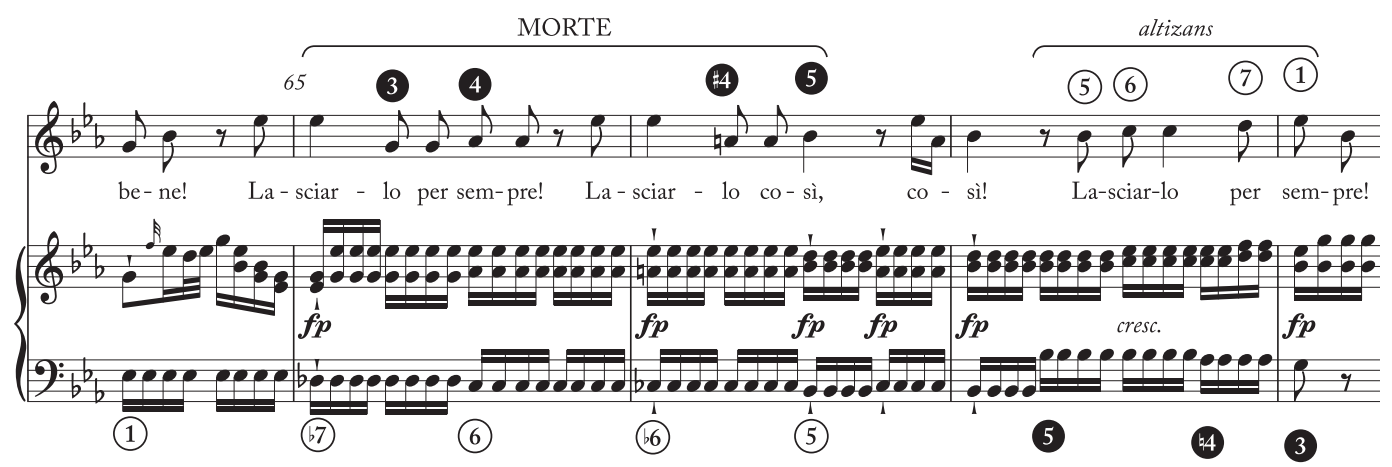

example 20. Andrea Bernasconi, L’Olimpiade (1764), Act II, Scene 10, "Se cerca, se dice," mm. 64-68

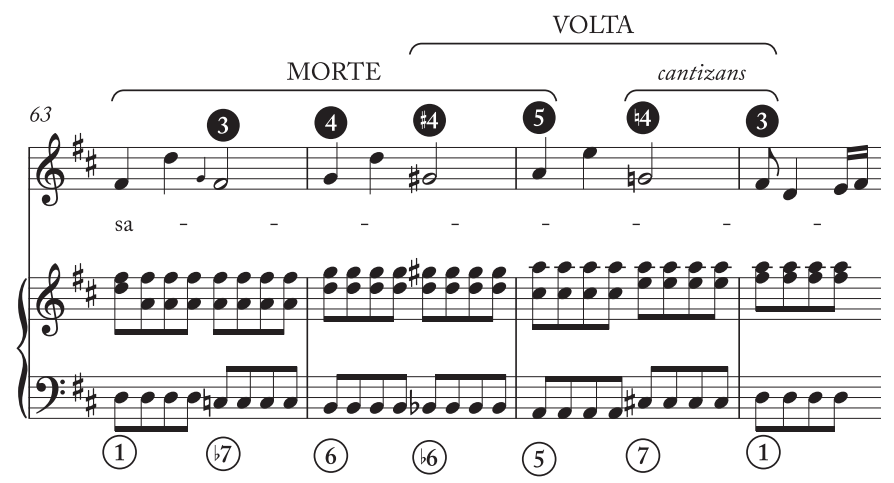

example 21. Hasse, Cleofide, Act III, Scene 6, "Cervo al bosco che piagato," mm. 63-66

divided into two component stages, the stability achieved at the end of its dominant-oriented charge stage is hierarchically subservient to the tonic closure achieved at the end of the schema's release stage; whereas a proper HC typically articulates closure at a level higher than Gjerdingen's surface-level schemas. But, as Poundie Burstein has repeatedly emphasized, half cadences are not all-or-nothing affairs, but instead reflect a range of dominant-ending closural effects, the interpretation of which "depends upon weighing the impact of ... various features that might conflict with one another." ${ }^{38}$ It thus seems prudent to adopt a heuristic that is flexible and based on a continuum of $\mathrm{HC}$ effects instead of a rigid, either/or distinction. That is, the more one detects a strong $\mathrm{HC}$ effect dividing a $\sharp \widehat{4}-\widehat{5}-\llbracket \widehat{4}-\widehat{3}$ string, the less one is likely to interpret that string with a single gestalt gesture, such as the Volta.

This fuzzy boundary between $\mathrm{HC}$ effects and the Volta schema is, in turn, intimately related to the schema's precadential formal function. This is because the action sequence "move to dominant (via $\sharp \widehat{4}$ ) $\rightarrow$ release to tonic (via $\measuredangle \widehat{4}$ )" routinely heralds impending cadences in the galant style, whether that action is stretched across multiple schemas and divided by an $\mathrm{HC}$ effect, or performed with a single foreground gesture like the Volta. In Heinrich Koch's late-eighteenth-century model of musical form, for instance, section-ending cadential

38 Burstein $(2015$, 89). See also Burstein (2014). phrases (what Koch calls a Schlußsatz) are often preceded by a prominent "resting point" on the dominant (ending a "Vphrase" or Quintabsatz). ${ }^{39}$ Example 22-an excerpt from Koch's "basic plan" (Anlage) for an aria from Graun's Der Tod Jesu—shows how a voltaic $\sharp \widehat{4}-\widehat{5}-\llbracket \widehat{4}-\widehat{3}$ bass string can materialize as a byproduct of this formal procedure: in this case, a Quintabsatz-ending converging cadence followed by a Schlußsatz-opening clausula altizans. ${ }^{40}$ Koch's model captures many characteristic musical patterns implicit not only in mature works by galant masters like Graun, but also within the basic pedagogical materials of the Neapolitan conservatories. Leonardo Leo's solfeggi, for instance, regularly feature what Hans Aerts describes as "a short digression to the dominant key that typically occurs within the run-up to the structural cadence and helps postpone it," an action that is frequently realized as a Volta-as shown in Example 23-but may be realized using other schemas as well. ${ }^{41}$ Thus, in the galant

39 Koch ([1787] 1983). Berger (2007) provides a classic introduction to Koch's paradigm and eighteenth-century punctuation form more generally. Koch's paradigm has enjoyed renewed interest in recent years; see Burstein (2015, 2016), Byros (2015), and Sherrill (2016).

40 Baker and Christensen (1995, 164-72). My labeling of this Anlage follows Sherrill $(2016,118-29)$ despite the fact that, as Burstein (personal communication) points out, the resulting $S c h l u \beta s a t z$ is too short to form a complete phrase in Koch's system. Nevertheless, Koch's Anlage is an abbreviation of Graun's actual composition, in which the converging cadence is clearly associated with an HC effect, and what is here labeled as a Schlußsatz is expanded to acceptable dimensions. The Anlage also removes seven measures of melismatic singing following the Quintabsatz, a procedure we will see again shortly (cf. discussion of Ex. 24).

4I Aerts (2017). Although Aerts (personal communication) believes that the Svago schema-his name for the dominant charge/tonic release paradigm in Leo's solfeggi - is identical to the Volta, the examples that he shared with the present author are not constrained by the same grouping principles that characterize our schema. For instance, one of Aerts's examples (Dresden A, No. 3, mm. 60-65) realizes the Svago paradigm as a full cadence to D followed by a ii-I Fonte in G, a configuration that allocates "dominant charge" and "tonic release" to two separate schematic gestalts. Hence, I believe that Aerts is describing a formal script that might be realized on the musical surface as a Volta, but could also be realized through some combination of other schemas. However, this hypothesis must remain preliminary until the results of Aerts's corpus study are published in full. 


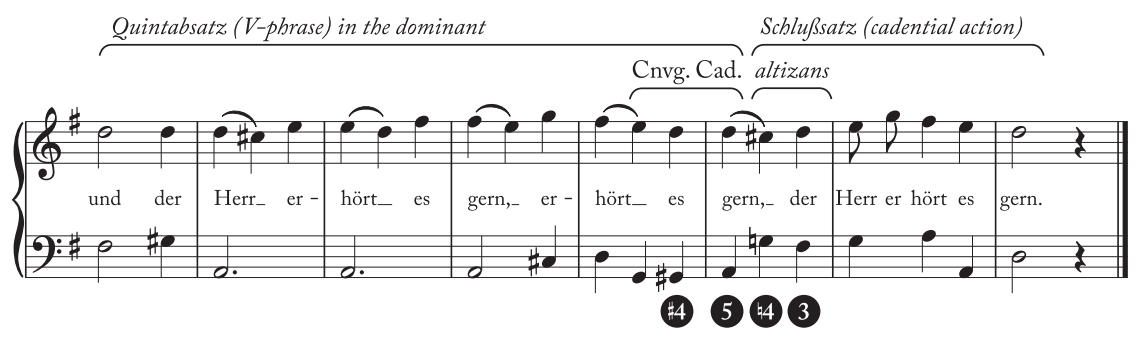

eXAmple 22. Carl Heinrich Graun, Der Tod Jesu (1755), "Ein Gebeth um neue Stärke," abridged by Koch

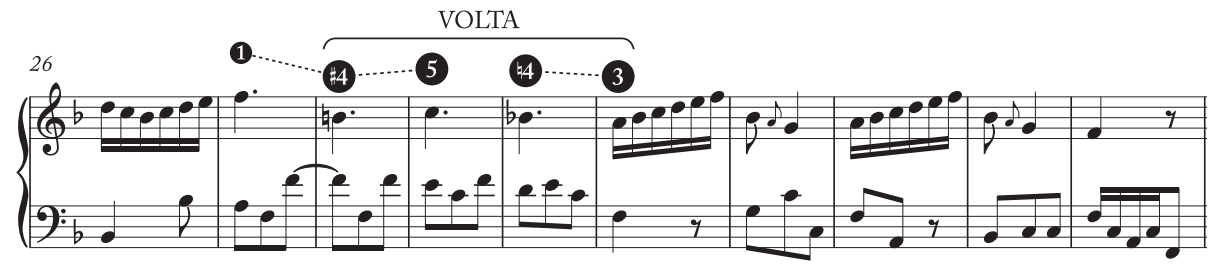

example 23. Leonardo Leo, Solfeggio in F Major, Dresden A, No. 27 (before 1744), mm. 26-35
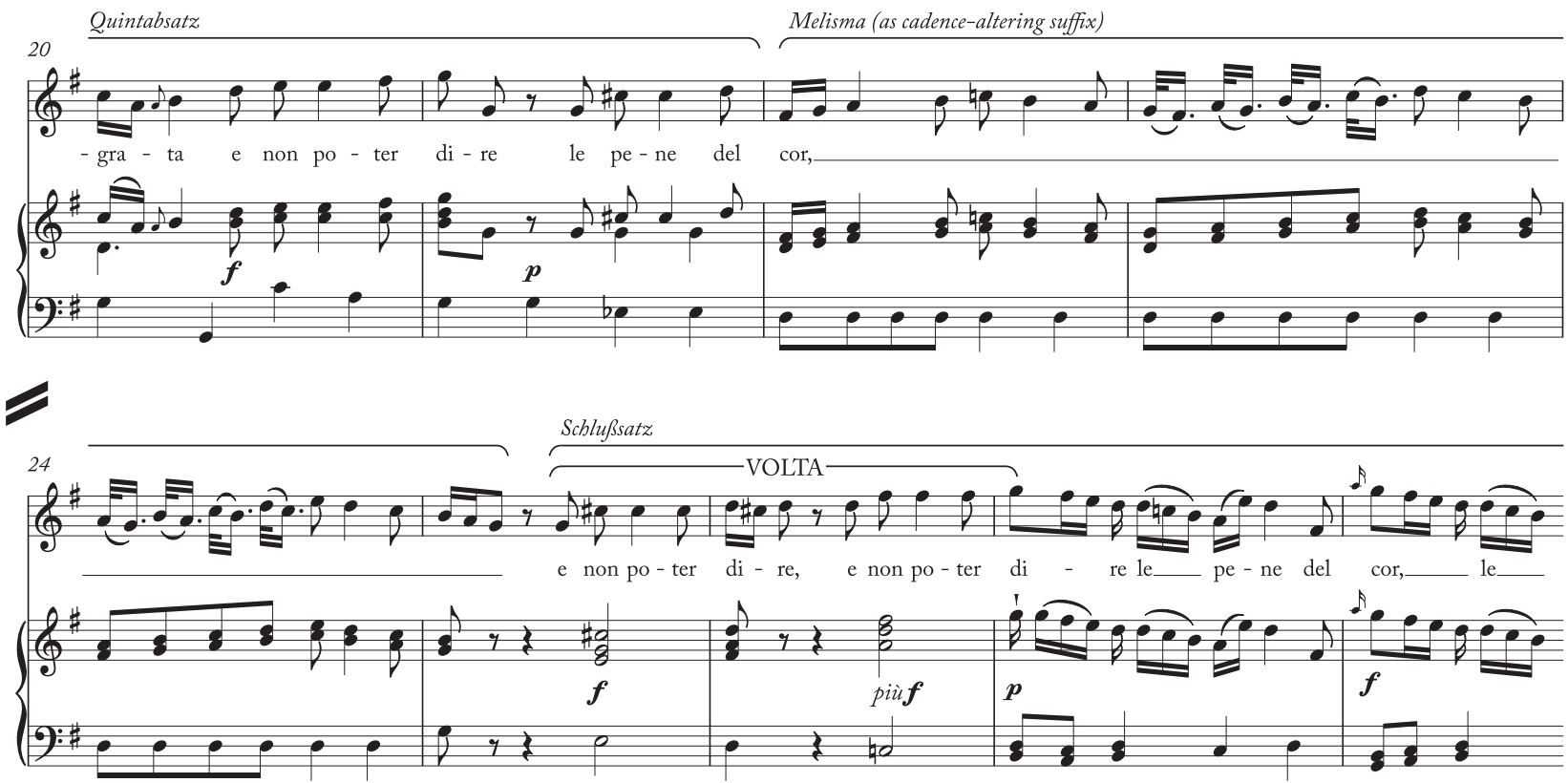

eXample 24. Hasse, Cleofide, “Che sorte crudele," mm. 20-28

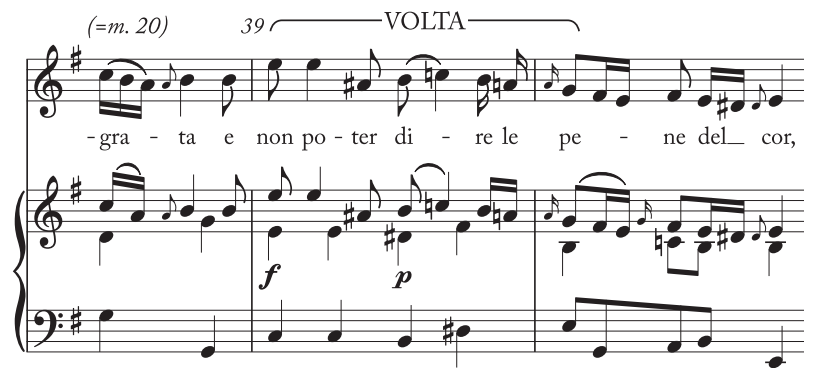

example 25. Hasse, Cleofide, “Che sorte crudele," mm. 38-40 style, $\sharp \widehat{4}-\widehat{5}-\downarrow \widehat{4}-\widehat{3}$ strings expressed a paradigmatic precadential harmonic action: articulating a local dominant and then passing away from that dominant to set up a cadential passage. The Volta, I hypothesize, emerged as a realization of that action, one that accomplished dominant charge and tonic release with parallel, rhyming clausulas.

According to this origin story, the Volta's prototypical formal function will be to bridge the end of a Quintabsatz to the beginning of a Schlußsatz. The Volta from Hasse's "Che sorte crudele" discussed above (Ex. 8) furnishes a particularly illustrative example of this paradigmatic function. Example 24 


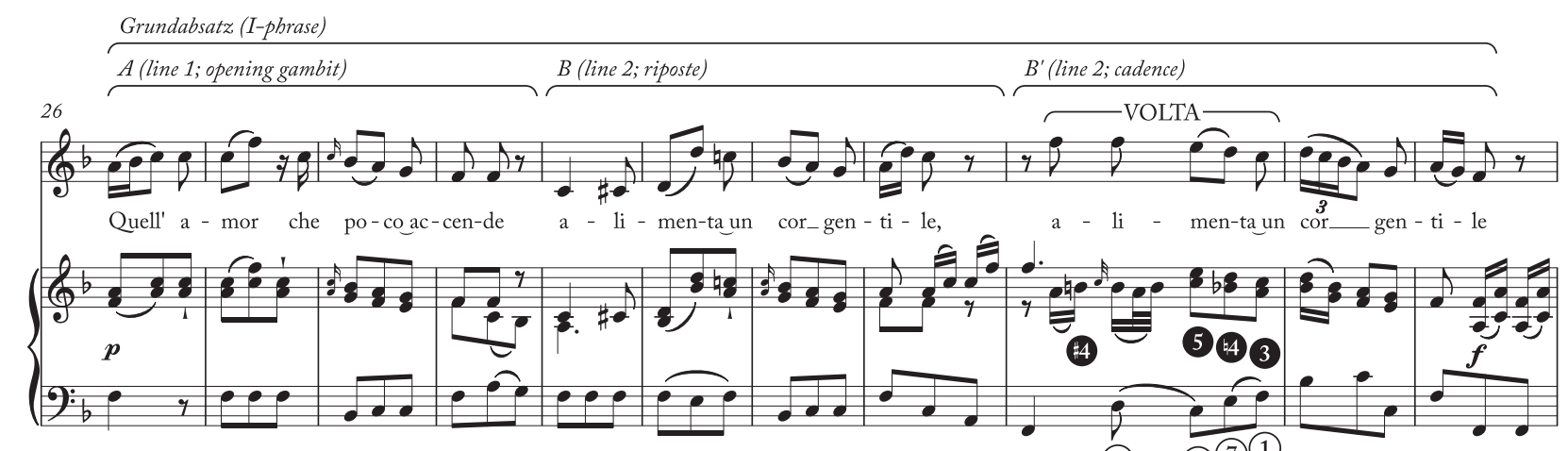

(6) (5)(1)

example 26. Johann Christian Bach, Catone in Utica (1761), Act III, Scene 4, "Quell'amor che poco accende," mm. 26-36
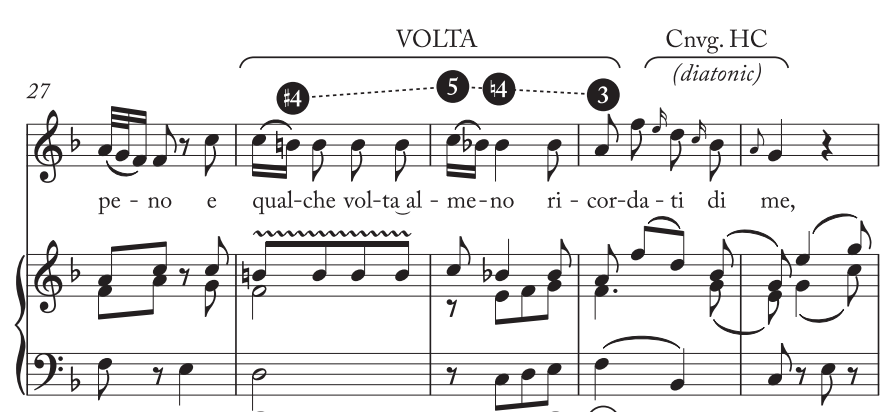

(6) ………….......(1)

eXAmple 27. Galuppi, Artaserse (1751), Act I, Scene 1,
"Conservati fedele," mm. 27-31

situates this Volta within its larger formal context. Hasse constructs the excerpt around a standard operatic extension of Koch's formal schema, inserting a melismatic passage between Quintabsatz and Scblußsatz. ${ }^{42}$ This melisma acts as a cadencealtering suffix, first expanding the HC achieved in m. 22 by standing on the dominant and then discharging to the tonic in m. 25. ${ }^{43}$ The Volta then enters, igniting the cadential energies of the Schlußsatz. Note how Hasse draws the second halves of m. 21 and m. 25 together through rhyming melodic and rhythmic profiles, as though $\mathrm{m}$. 25 had reset the formal clock to $\mathrm{m}$. 21. These associations suggest that the Volta acts here as a compressed summary of the preceding dominant-oriented actions, returning to a moment of dominant articulation and then quickly pushing onward to the cadential progression.

The Volta plays an important role in the second vocal period as well, as shown in Example 25. After a four-measure modulatory unit that runs in parallel with the first vocal period (mm. 34-38=mm. 16-20), Hasse deploys a Volta to wrest the tonality forcibly back to $\mathrm{E}$ minor, which is then immediately secured with a PAC. ${ }^{44}$ In this way, Hasse's allusion to

42 Sherrill (2016, 174-76).

43 Rothstein (1989).

44 The cadence in m. 40 is subsequently rejected by an augmented sixth that resets rotational progress, again recalling the events of $\mathrm{m}$. 25, after which
Quintabsatz compression in the first vocal period is actualized in the second-both excerpts push toward a strong dominant before releasing into a cadence, but this action is stretched across multiple schemas in the former and succinctly executed by a Volta in the latter. The Volta can thus be understood as a "miniaturized" version of characteristic chromatic events in the Quintabsatz $\rightarrow$ Schlußsatz juncture, concentrating this formal script's chromatic energies to forcefully open cadential space.

Formal scripts, as top-down constraints on musical event sequences, motivate the deployment or development of surface constructions that are particularly useful for realizing specific formal actions. ${ }^{45}$ Perhaps many schemas, or collocations of several schemas, never detach from their generating formal slots, and as a result could be understood primarily as subsets of a larger form-functional category. ${ }^{46}$ The Volta, however, is not one of those schemas: whatever its origin, it was eventually treated as an independent gestalt, perhaps because it has a memorable structure-in large part due to its fusion of rhyming melodic gestures with attention-grabbing chromaticismthat makes it easy to learn, recall, and use. The schema's independent status is confirmed by the fact that it could be detached from its original formal slot and appear before cadential events that are not typically telegraphed by the Quintabsatz $\rightarrow S$ Schlu $\beta$ satz script; for instance, to announce a cadence that closes an extended tonic phrase (or Grundabsatz) at

the missing dominant pedal is restored (mm. 43ff.). Measure 48 then presents a distorted take on the aria's Volta motive, inserting a clausula to A between the prototypical dominant charge and tonic release stages.

45 Byros $(2015,227)$ communicates a similar principle when he writes: "higher-level subschemata ... have a top-down influence on lower-level, embedded forms of syntax-or, from the other way round, lower-level forms of syntax have a bottom-up obligation to communicate the [formal] script."

46 As an example, Gjerdingen and Bourne's (2015, "Grammatical Constructions") Final Fall schema-a "bringing down the house" construction in works by Arensky, Rachmaninoff, and others that fuses virtuosic figuration, descending contour, and a harmonic profile defined by a persistent $\mathrm{C}$-major harmony with dissonant $\mathrm{F} \sharp$ and $\mathrm{A}$ colorations-is described as a fundamentally piece-concluding gesture; one not easily transferred to other formal slots. 


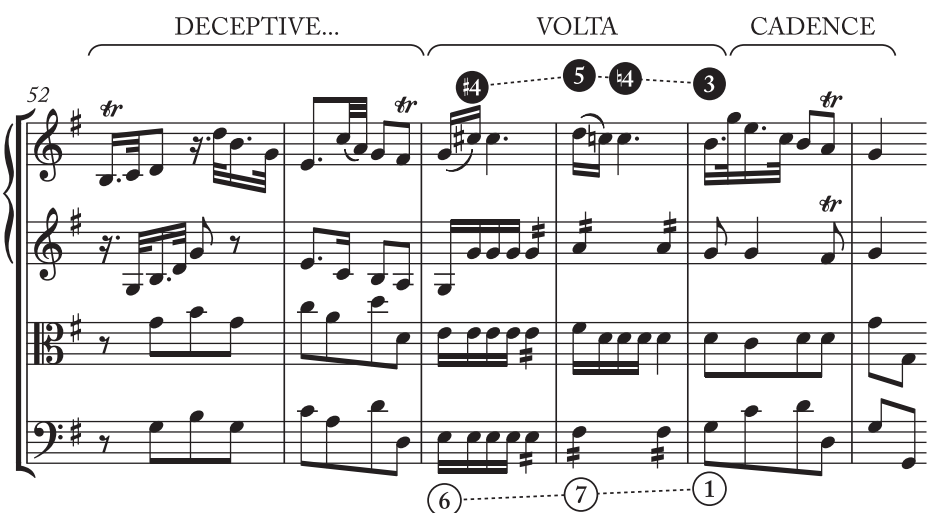

EXAMPle 28. Haydn, Symphony No. 18 in G Major, first movement, mm. 52-57

\begin{tabular}{l|l|l} 
Default level: & Functional description: & Schematic representation: \\
\hline High-level default & Quintabsatz $\rightarrow$ Schlu $\beta$ satz bridge & $\mathrm{HC} \rightarrow$ VOLTA $\rightarrow$ PAC \\
Mid-level defaults & Precedes non-Schlußsatz PAC & $\mathrm{X} \rightarrow$ VOLTA $\rightarrow$ PAC \\
& "One More Time" bridge & vi $\rightarrow$ VOLTA $\rightarrow$ PAC \\
Low-level default & Precedes HC & $\mathrm{X} \rightarrow$ VOLTA $\rightarrow$ HC \\
Deformational & No cadence follows & $\mathrm{X} \rightarrow$ VOLTA $\rightarrow \mathrm{X}$
\end{tabular}

EXAMPLE 29. Summary of the Volta's formal functions

the beginning of a vocal period, as in Example $26,{ }^{47}$ or as a pre-cadential schema within a brief ritornello (Examples 3, $8[\mathrm{a}], 11[\mathrm{~b}]$, and 16). Thus, although the Volta may have emerged initially to fill a specific formal slot-forecasting rotation-concluding cadential events-it eventually came to have a more independent existence as a general cadencesignaling device.

The Volta's formal function can, like its pitch structure, be modeled as a category with a central prototype and motivated extensions. The preceding discussion highlighted the schema's prototypical function-a Quintabsatz $\rightarrow S$ Shlußsatz bridge-as well as a basic principle of cadential abstraction that broadens its horizons to include any pre-PAC slot. This motivating principle may be applied again to produce a more distant extension; any $P A C$ abstracts to any cadence, thus allowing the Volta to herald the approach of an $\mathrm{HC}$, a possibility shown in Example 27. Example 28 illustrates a separate extension from the central prototype afforded by aspects of the schema's pitch structure: that is, because several common Volta bass strings proceed from $\widehat{6}$ (either descending $\widehat{6}-\widehat{5}-\widehat{4}-\widehat{3}$ or ascending $\widehat{6}-\widehat{7}-\hat{1})$, Voltas commonly participate in what Janet Schmalfeldt calls the "One More Time" technique, bridging a

47 This opening phrase articulates a characteristically galant ABB phrase structure, as discussed by Weimer (1984) and Sherrill (2016). This phrase type is also evident in mm. 1-3 of Ex. 1, where it is expressed as a "Romanesca-Evaded Cadence-Cadence" event sequence. deceptive cadence back to tonic in preparation for a second cadential approach. ${ }^{48}$ Example 29 collates these functions as a hierarchy of functional defaults-the more distant the extension, the more marked its occurrence in the style. Any instance of a Volta that does not proceed onto a cadential progression should typically be regarded as an extremely marked or even deformational circumstance, and must therefore be interpreted on an individual basis. One such case is analyzed at the end of this article, in the discussion of Example 33 below. ${ }^{49}$

\section{A GESTURE OF CULMINATION}

Most enquiries into the semantic possibilities of schemas have focused on potential associations between a given schema and a musical topic. ${ }^{50}$ For instance, Olga Sánchez-Kisielewska has convincingly demonstrated that, in the last third of the eighteenth century, the Romanesca schema correlates strongly with the "sacred hymn" topic, and thus to hear the Romanesca's

48 Schmalfeldt (1992). As such cadential loops telegraph strong cadences, they tend to cluster around the structurally significant cadences at the ends of major sections. As a result, Voltas functioning as a "One More Time" bridge tend to appear before Schlußsatz PACs, just like the prototypical case.

49 On default levels and deformations, see Hepokoski and Darcy (2006); on markedness, see Hatten (1994).

50 Gjerdingen (2007, cf. discussion of the Pastorella schema), Byros (2014), Bourne (2017), Rice (2017). 


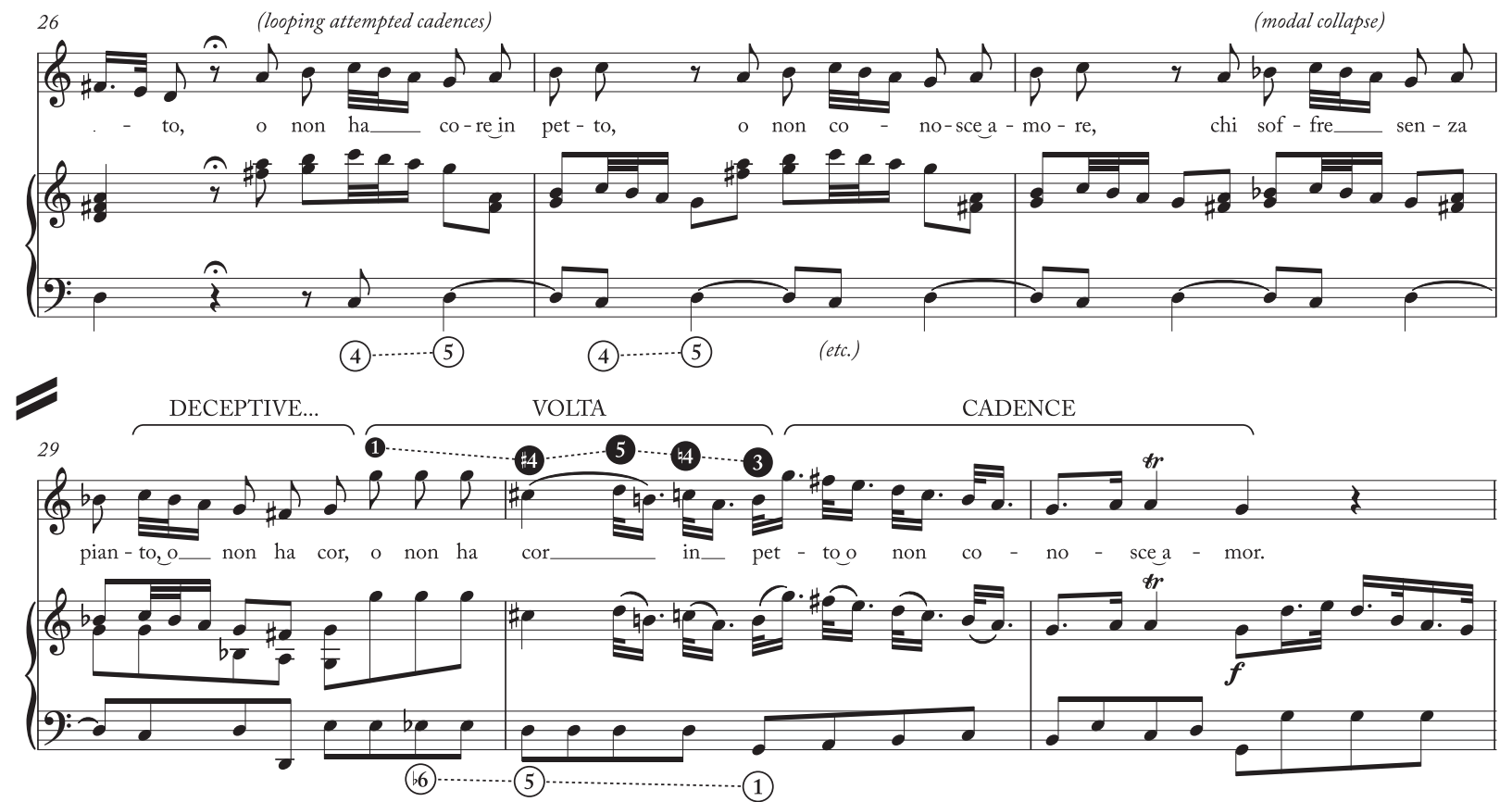

example 3o. Pergolesi, Adriano in Siria (1734), Act I, Scene 11, "Chi soffre senza pianto," mm. 26-31

characteristic melodic strings was to hear echoes of the sacred style. ${ }^{51}$ Nonetheless, most schemas, including the Volta, do not have strong topical implications. In Example 11 alone, we observed Voltas accompanying lilting pastoral dances (Exs. $11[\mathrm{e}]$ and $11[\mathrm{~g}]$ ) just as often as tempestuous rage arias (Exs. $11[\mathrm{a}]$ and $11[\mathrm{f}])$. Such topical ambivalence may be a consequence of the schema's mid-to-late formal function, since topics tend to be most strongly articulated at phrase beginnings. ${ }^{52}$ But topical equivocality must not be confused with expressive neutrality. This is because schemas, as the foreground "stuff" of eighteenth-century music, unfold a topic over time. It is only through schemas that the semantic possibilities of a topic are shaped into a tangible expressive utterance. Thus, even topically neutral schemas have much to reveal about the semantic shape of a phrase over time and should therefore be central in expressive analyses.

5I Sánchez-Kisielewska (2016).

52 This is especially true for opera seria, which characteristically features a limited topical palette for each aria, whereas buffa works are much more amenable to mid-phrase shifts in topical discourse, as Allanbrook (1983, 2014) has repeatedly emphasized. An additional consequence of its late formal position is that the Volta tends to be deployed in conjunction with words that have already been heard in conjunction with other schemas. As a result, an approach that maps a schema's meaning onto the words it typically colors-like the one adopted by Rice (2014) for the Heartz schema-is not possible for the Volta. This is because the words that the schema sets will be constrained by their relative proximity to the conclusion of a poetic unit, rather than their particular semantic significance. Sherrill (2016) makes a similar argument concerning the distribution of melismatic singing in galant arias.
The Volta typically acts as a rhetorical marker of climax, providing a powerful swell of energy preceding the relative comforts of stock cadential schemas. Some Voltas, as we saw in our very first example from Pergolesi's Stabat Mater, produce musical climax through a prominent expressive reversal, similar to antithesis in classical rhetoric or peripeteia in Aristotelian poetics. Others amplify an existing affective profile to its expressive limit, summoning intense vocal gestures and potent chromatic juxtapositions as markers of deep sensibility or emotional distress. In the following section, I explore these interpretive paradigms as performed by three arias from the 1730s, painting a partial—but still, I hope, suggestive - picture of the schema's semantic potency as a rhetorical device in galant opera.

Reversal is a key element in musical climax, at the very least since a climactic moment marks the moment of reversal from energy-gaining processes to energy-releasing ones. ${ }^{53}$ The Volta participates in reversal effects in several ways, most obviously through the built-in melodic reversal attending the schema's core $\sharp \widehat{4}-\widehat{5}-\llbracket \widehat{4}-\widehat{3}$ string. Two features of the Volta's syntactical profile also contribute to its association with expressive reversal. First, because the Volta carries strong implications for cadential continuation, its appearance may herald a dramatic snap from uncertain to certain processes, clarifying the path forward following periods of fraught turbulence.

53 David Huron (2006, 326) characterizes climax as "a dramatic limbic reversal" that represents "the epitome of contrastive valence in music making." Likewise, Meyer (1956, 171; 1973, 119) connects reversal to musical climax on several occasions, arguing that reversal acts to break potentially endless processes and thereby clarify a path toward an impending musical goal. 


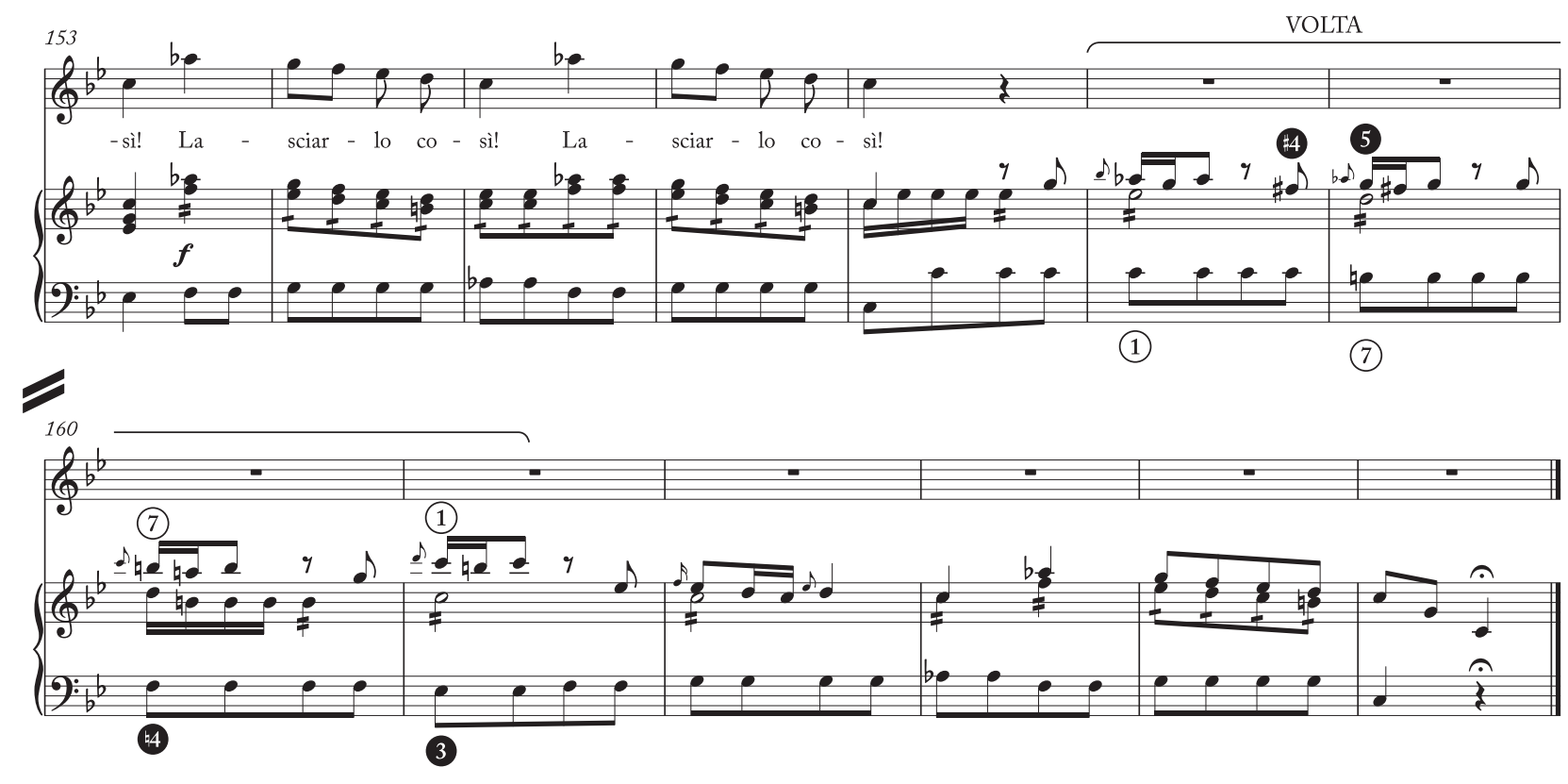

eXample 31. Pergolesi, L’Olimpiade (1735), Act II, Scene 10, “Se cerca, se dice,” mm. 153-65

Second, while the initial $\sharp \widehat{4}$ charge admits of modally mixed contrapuntal support-especially $b \widehat{6}$ and $b \widehat{3}$ - the $\measuredangle \widehat{4}$ release invariably concludes on a modally correct tonic. The schema is thus well suited to the task of absorbing the minor mode and restoring the proper modal collection.

We may observe these features in action in "Chi soffre senza pianto" from Pergolesi's Adriano in Siria. The first vocal period's Schlußsatz-shown in Example 30-launches with a looping series of incomplete cadences, building a massive swell of energy by continuously blocking cadential resolution. ${ }^{54} \mathrm{At}$ m. 28, these loops suffer modal collapse when B is deflected to $\mathrm{B} b$, after which a deceptive cadence brings a further frustration of the cadential impulse. The phrase's pent-up energy is discharged in the climactic Volta of mm. 29-30, which absorbs the minor mode with an implied augmented sixth, brings the boiling tension to its apex with the astonishing force of a $\mathrm{C} \sharp /$ $\mathrm{D}$ dissonance, and subsequently clears Sabina's path to cadential fulfillment. The Volta thus marks the moment that Sabina's musical fortunes reverse: it is the means by which she overcomes her inhibitions, frees herself from the suffocating threat of the minor mode, and conducts herself toward the rational light of a successful cadence.

As a rhetorical signal of climax, the Volta frequently appears in arias of special dramatic import. Such is the case in Pergolesi's "Se cerca, se dice," an aria of such fame that, according to Stendhal, it continued to be "known by heart in all of Italy" well into the nineteenth century. ${ }^{55}$ The aria,

54 We might understand the cadential loops as what Meyer (1956, 135) would call "saturation," where "a figure which is repeated over and over again arouses a strong expectation of change both because continuation is inhibited and because the figure is not allowed to reach completion."

55 Stendhal $(1839,428)$. suffused throughout with pathetic musical expression, stages the primo uomo's impassioned final farewell to his beloved before he quits the stage in despair to take his own life. As shown in Example 31, the concluding ritornello launches with a powerful wedged Volta, which bursts through the $\mathrm{Ab}$ registral ceiling that capped the singer's melodic actions at the very moment that the hero's internal strife explodes into the physical action of a stage exit. Just as Megacle's horrific attempted suicide both results from and enacts the profound emotional conflicts worked out over the course of the aria, so too does the Volta provide a succinct summary of the aria's musical pathos, standing as a sonic analogue both for the emotional conflicts that have unfolded before us, and for a future action so horrific that it must be hidden from view on the wings of the stage. ${ }^{56}$

The Volta also functions as a global musical climax in Vinci's Artaserse. The opera's final major musical number (excluding the perfunctory final chorus) is also its only duet, "Tu voi ch'io viva o cara," which again concerns the central amorous conflict between prima donna and primo nomo. Whereas Pergolesi's "Se cerca, se dice" concludes with an unseen suicide attempt, this scene begins as Arbace, falsely accused of murdering his beloved Mandane's father, blocks the princess's suicidal impulse. Although Mandane's filial devotion prevents her from forgiving Arbace, her actions and physical demeanor reveal the love that still burns within her breast. The duet itself stages this process of unspoken reconciliation, as Mandane grants through musical actions the forgiveness that she cannot express in words. As in "Se cerca, se dice," Vinci launches the concluding ritornello with a Volta, but in this case, the 

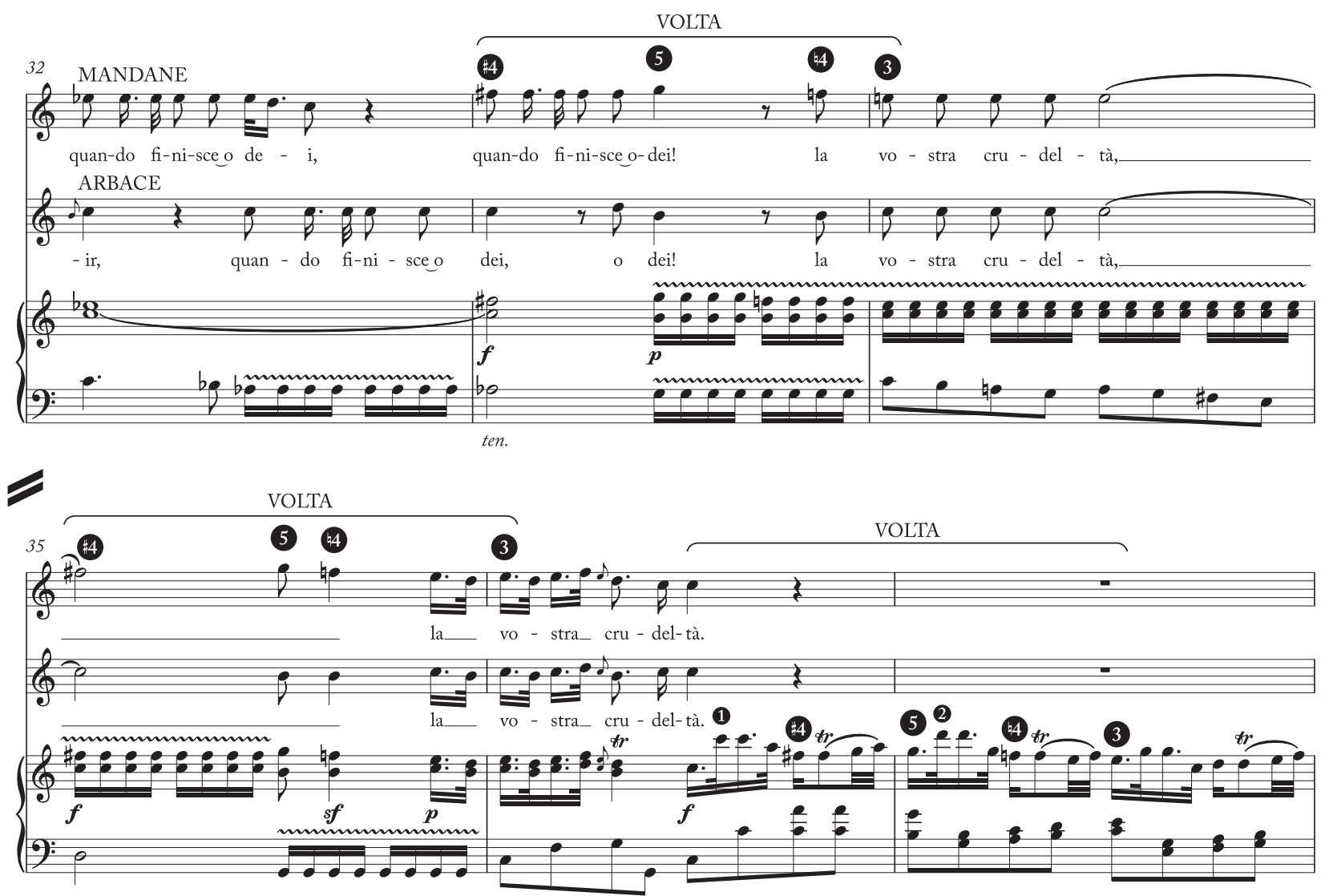

example 32. Vinci, Artaserse (1730), Act III, Scene 7, "Tu vuoi ch'io viva o cara," mm. 32-37

ritornello follows a torrent of Voltas that accomplish crucial rhetorical actions in the preceding phrase, seen in Example 32. The first of these heals the wounds of modal collapse, transforming the minor tonic of $\mathrm{m}$. 32 into an augmented-sixth charge and releasing into a modally rectified tonic. The second Volta then stages the couple's first action as a homophonic unit, drawing the pair together in rhythmic communion in conjunction with the aria's first and only instance of melismatic singing. ${ }^{57}$ After these two periods of emotional intensity, the following cadential stamp comes on like a breath of fresh air, paving the way for the lovers to wed their voices on a unison $\mathrm{C}$ at the end of the phrase.

In this astonishing swell of voltaic activity, $\sharp \widehat{4}$ and $\downarrow \widehat{4}$ yield to one another again and again, mapping perhaps onto the centrifugal and centripetal forces of filial duty on the one hand and passionate love on the other that drive the central

57 Note that mm. 32-36 articulate a second, complete attempt at musical closure. The first cadential attempt at $\mathrm{m}$. 30 comes on the heels of a rotationally equivalent passage featuring two Voltas performing the same rhetorical actions, except that the first Volta in this instance (mm. 25-27) is not preceded by a modal collapse. This lends credence to my interpretation of the Volta at $\mathrm{m} .33$ as an attempt to fix the modal collapse of $\mathrm{m}$. 32 , since the action taken in response to this modal blockage is to revert to a point in the rotational plan that was originally successful in sustaining the aria's modal propriety. emotional conflict of the entire opera. But beyond merely representing emotional turmoil, the Volta is actively used by these lovers to unite their souls in harmony and uncover a successful path to the cadential denouement. With the Volta, then, Arbace and Mandane discover the delicate balance that must be struck between opposing psychological impulses in order to lead a happy existence, revealing themselves to be the very model of enlightened courtship.

In the preceding analyses, a few basic hermeneutic premises-especially the metaphorical mapping of tonal process onto purposeful human action-opened several avenues for engaging the Volta's narrative significance in opera seria. ${ }^{58}$ Rather than argue that the Volta has an identifiable expressive meaning that it carries from one situation to another (heroes despairing, lovers uniting), I instead claim that the Volta strongly correlates with rhetorical climax, and thus its meaning results contextually from the way musical climax functions within the

$5^{8}$ Hepokoski and Darcy (2006) frame the late-eighteenth-century sonata from this narrative angle. Their hermeneutic approach was refined with specific reference to opera seria by Sherrill (2016), who interprets the rhetoric of galant arias as the therapeutic process by which pathological passionate excess is worked out and made comprehensible through closed and well-structured musical processes, thus freeing characters from the emotional paralysis that occasioned the aria moment and granting the action of a stage exit. 


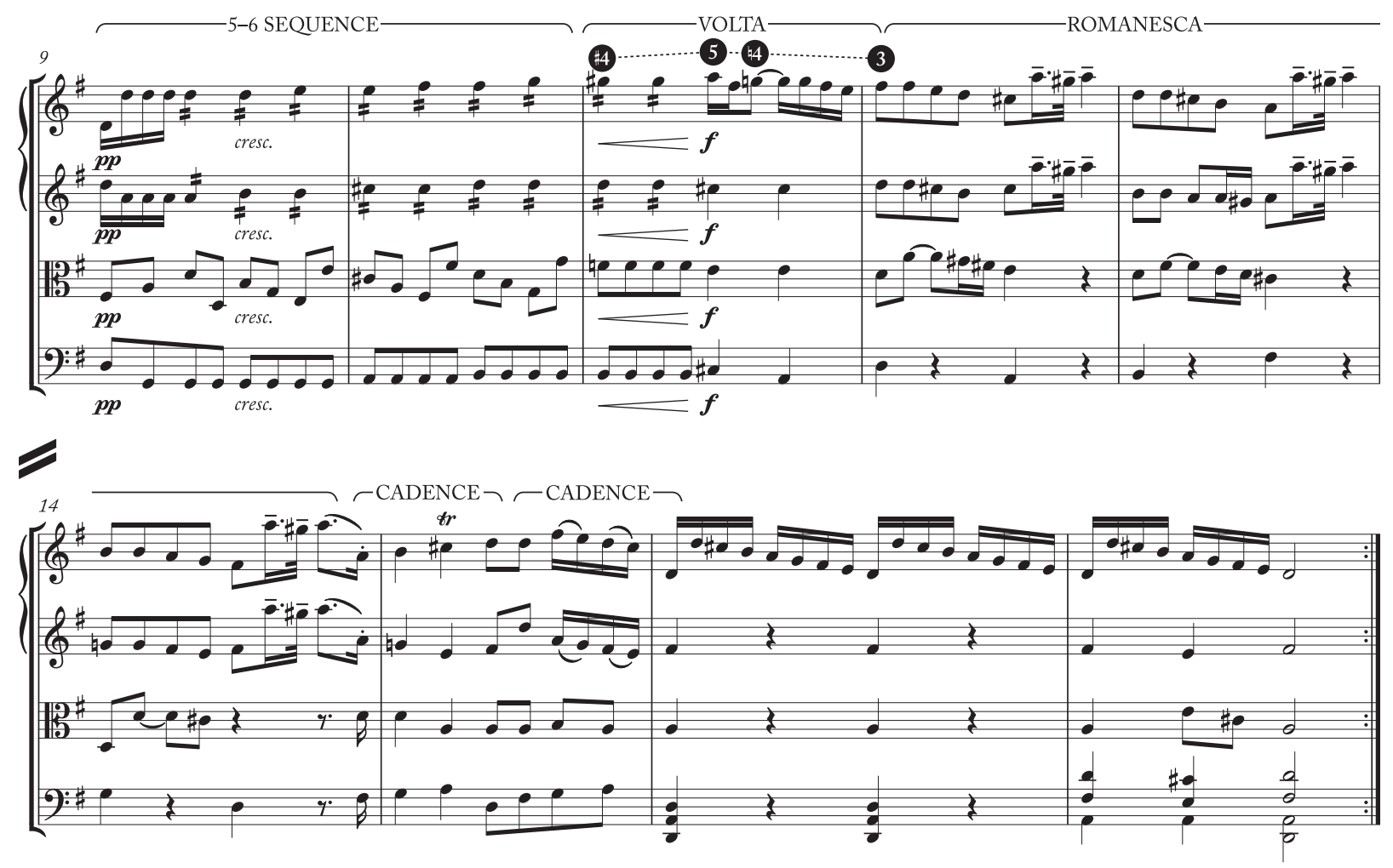

EXAMPle 33. Giovanni Battista Sammartini, Symphony in G Major, J-C. 39, first movement, mm. 9-17

expressive universe and dramatic context of each individual aria. $^{59}$ This emphasis on hermeneutic interpretation, though quite foreign to the mode of schematic engagement that Gjerdingen advances in Music in the Galant Style, has seen growing interest in recent years, with studies by Michael Spitzer, Vasili Byros, Janet Bourne, and James Palmer, among others offering many diverse models for hermeneutic interpretation that explicitly engage music's surface constellation of schemas. ${ }^{60} \mathrm{I}$ offer the brief analyses above as a case study in the semantic affordances of one schema-an especially useful one given its association with musical climax-through which I hope to have illustrated just some of the potential lines of inquiry that schemas open for hermeneutically engaged analysis of eighteenth-century opera.

\section{CONCLUSION: SCHEMAS AND TEMPORALITY}

In this article, I have used the Volta to open a window onto several facets of galant music-making: illustrating how central features of a schematic prototype enable certain paths for creative variation and elaboration, showing how composers constructed gestures that call out to multiple basic prototypes,

59 This climactic function need not be interpreted narratively. In fact, in my analysis of "Pupillette vezzosette" (Ex. 4), I argued instead that the Volta's climactic rhetoric activates audience sensibilities and thereby enables a moment of intimate communion with the singer's voice.

6o Spitzer (2008), Byros (2013, 2014), Bourne (2016), Palmer (2017). exploring the links between foreground schemas and scripted event sequences on higher structural levels, and highlighting the use of schemas to perform musical narratives in operatic contexts. Furthermore, both the formal and rhetorical meanings I have claimed for the schema-as a signal of impending cadential closure and as a gesture of culmination, respectively - are tightly bound to music's temporality. That is, these meanings index a teleological orientation toward musical time, in which musical energies direct listener attention toward the climactic achievement of syntactical goals. The Volta asks analysts to be sensitive to the kinds of temporality that galant music can express, to consider how a piece's cadential goals are telegraphed and forecasted by the events that precede them.

I close with an example that illustrates the teleological play that the Volta affords. The first movement of Sammartini's Symphony in G Major features a Volta that does not proceed immediately to a cadence-see Example 33-but yields instead to a luxurious Romanesca in full "Pachelbel" garb. While this Volta is deformationally severed from its cadential mate, its semantic role as a gesture of culmination remains intact: the Volta serves as the electrifying cap to the 5-6 sequence in $\mathrm{mm}$. 9-10. This Volta, then, acts as the fulcrum for a fundamental shift in temporal orientation; it absorbs the forward-directed, teleological impulse of the preceding sequence, allowing the Romanesca that follows to retreat into a pensive, lyrical mode. If we adopt Karol Berger's view that the eighteenth century was a crucial turning point in Western attitudes toward 
musical time-from undirected, "cyclical" time to the teleological directionality of "linear" time-then Sammartini's Symphony dramatizes that dichotomy by staging a change in perspective, a sudden turn from the directed to the cyclical, pirouetting on the Volta. ${ }^{61}$ In this way, a deformational sequence of schemas on the musical foreground directs our attention to a delicate interplay of temporal energies at higher discursive levels.

Whether we are grappling with the complexities of musical temporality, the expressive impact of an operatic aria, or the trajectory of formal section, we must recognize that each of these musical concerns is given life at the musical surface through a rich lexicon of conventionalized musical constructions. And this is the real charge of Gjerdingen's project; that detailed "microhistories" and "microtheories" formed in response to specific schemas are essential for any serious inquiry into the communicative processes that linked composers, performers, and audiences in the long eighteenth century. ${ }^{62}$

\section{WORKS CITED}

Aerts, Hans. 2017. "The Svago: Methodological Reflections on a Schema in Solfeggi by Leonardo Leo (1694-1744)." Paper presented at the 9th European Music Analysis Conference, June 28-July 1, Strasbourg.

Agawu, Kofi. 2014. "Topics and Form in Mozart's String Quintet in E-Flat Major, K. 614/i." In The Oxford Handbook of Topic Theory. Ed. Danuta Mirka. 474-92. Oxford: Oxford University Press.

Allanbrook, Wye Jamison. 1983. Rhythmic Gesture in Mozart: Le nozze di Figaro and Don Giovanni. Chicago: University of Chicago Press.

- 2014. The Secular Commedia: Comic Mimesis in Late Eighteenth-Century Music. Berkeley: University of California Press.

Bach, Carl Philipp Emanuel. [1753/1762] 1949. Essay on the True Art of Playing Keyboard Instruments. Trans. and Ed. William J. Mitchell. New York: Norton.

Baker, Nancy Kovaleff and Thomas Christensen, eds. 1995. Aesthetics and the Art of Musical Composition in the German Enlightenment: Selected Writings of Johann Georg Sulzer and Heinrich Christoph Koch. Cambridge: Cambridge University Press.

Berger, Karol. 2007. Bach's Cycle, Mozart's Arrow: An Essay on the Origins of Musical Modernity. Berkeley: University of California Press.

6I Berger (2007). The passage mm. 12-14 suggests cyclical time in particular due to the root position sonorities, broad harmonic rhythm, and tonic prolongational function, all of which tie the passage to the Romanesca's origins as a "cyclical" ground-bass pattern.

62 Gjerdingen (2007, 435); Byros (2017). On the relationship of Gjerdingen's scholarship to the larger intellectual currents of what Byros calls the "Penn School," see Byros (2012).
Berkowitz, Aaron. 2010. The Improvising Mind: Cognition and Creativity in the Musical Moment. Oxford: Oxford University Press.

Bermann, Sandra L. 1988. The Sonnet over Time: A Study in the Sonnets of Petrarch, Shakespeare, and Baudelaire. Chapel Hill: University of North Carolina Press.

Bourne, Janet. 2016. "Perceiving Irony in Music: The Problem in Beethoven's String Quartets." Music Theory Online 22 (3).

- 2017. "The Schema-Topic Construction.” Paper presented at the 9th European Music Analysis Conference. June 28-July 1, Strasbourg.

Burney, Charles. 1773. The Present State of Music in Germany, the Netherlands, and United Provinces. Vol. 1. London: T. Becket and Co., J. Robson, and G. Robinson.

-1789. A General History of Music from the Earliest Ages to the Present Period. Vol. 4. London: Payne and Son, Robson and Clark, and G. G. J. and J. Robinson.

Burstein, Poundie. 2014. "The Half Cadence and Other Such Slippery Events." Music Theory Spectrum 36 (2): 203-27.

- 2015. "The Half Cadence and Related Analytic Fictions." In What Is a Cadence?: Theoretical and Analytical Perspectives on Cadences in the Classical Repertoire. Ed. Markus Neuwirth and Pieter Bergè. 85-116. Leuven: Leuven University Press.

- 2016. "Expositional Journeys and Resting Points." In A Composition as a Problem 7: Proceedings of the Seventh International Conference on Music Theory: Tallinn, Pärnu, January 8-11, 2014. Ed. Mart Humal. 5-16. Tallinn: Spin Press.

Byros, Vasili. 2009. “Towards an 'Archaeology' of Hearing: Schemata and Eighteenth-Century Consciousness." Musica Humana 1 (2): 235-306.

- 2012. "Meyer's Anvil: Revisiting the Schema Concept." Music Analysis 31 (3): 273-346.

—. 2013. "Trazom's Wit: Communicative Strategies in a 'Popular' Yet 'Difficult' Sonata." Eighteenth-Century Music 10 (2): 213-52.

- 2014. "Topics and Harmonic Schemata: A Case from Beethoven." In The Oxford Handbook of Topic Theory. Ed. Danuta Mirka. 381-414. Oxford: Oxford University Press.

- 2015. "Hauptruhepuncte des Geistes': Punctuation Schemas and the Late-Eighteenth-Century Sonata." In What Is a Cadence?: Theoretical and Analytical Perspectives on Cadences in the Classical Repertoire. Ed. Markus Neuwirth and Pieter Bergè. 215-52. Leuven: Leuven University Press.

- 2017. "Mozart's Vintage Corelli: The Microstory of a Fonte-Romanesca." Intégral 31: 63-89.

Caplin, William. 2000. Classical Form: A Theory of Formal Functions for the Instrumental Music of Haydn, Mozart, and Beethoven. Oxford: Oxford University Press.

Ciolfi, Simone. 2011. "Formule e improvvisazione nei recitativi del Cantate di Alessandro Scarlatti." In Beyond Notes: Improvisation in Western Music of the Eighteenth and Nineteenth Centuries. Ed. Rudolf Rasch. 83-96. Turnhout: Brepols. 
Decock, Lieven and Igor Douven. 2014. "What Is Graded Membership?" Noûs 48 (4): 653-82.

Douven, Igor, Lieven Decock, Richard Dietz, and Paul Égré. 2013. "Vagueness: A Conceptual Spaces Approach." Journal of Philosophical Logic 42 (1): 137-60.

Gjerdingen, Robert. 1988. A Classic Turn of Phrase: Music and the Psychology of Convention. Philadelphia: University of Philadelphia Press.

- 2007. Music in the Galant Style. Oxford: Oxford University Press.

Gjerdingen, Robert and Janet Bourne. 2015. "Schema Theory as a Construction Grammar." Music Theory Online 21 (2).

Hatten, Robert. 1994. Musical Meaning in Beethoven: Markedness, Correlation, and Interpretation. Bloomington: Indiana University Press.

Heartz, Daniel. 1999. "A Venetian Dancing Master Teaches the Forlana: Lambranzi's Balli Teatrali." Journal of Musicology 17 (1): 136-51.

- 2003. Music in European Capitals: The Galant Style 1720-1780. New York: Norton.

Hepokoski, James and Warren Darcy. 2006. Elements of Sonata Theory: Norms, Types, and Deformations in the LateEighteenth-Century Sonata. Oxford: Oxford University Press.

Huron, David. 2006. Sweet Anticipation: Music and the Psychology of Expectation. Cambridge, MA: MIT Press.

Koch, Heinrich Christoph. [1787] 1983. Introductory Essay on Composition: The Mechanical Rules of Melody. Sections 3 and 4. Trans. Nancy Kovaleff Baker. New Haven: Yale University Press.

Lakoff, George. 1987. Women, Fire, and Dangerous Things: What Categories Reveal about the Mind. Chicago: University of Chicago Press.

Little, Meredith and Natalie Jenne. 2009. Dance and the Music of J. S. Bach, Expanded Edition. Bloomington: Indiana University Press.

Markstrom, Kurt Sven. 2007. The Operas of Leonardo Vinci, Napoletano. Hillsdale, NY: Pendragon Press.

Meyer, Leonard B. 1956. Emotion and Meaning in Music. Chicago: University of Chicago Press.

- 1973. Explaining Music: Essays and Explorations. Chicago: University of Chicago Press.

- 1989. Style and Music: Theory, History, and Ideology. Chicago: University of Chicago Press.

Meyer, Leonard B. and Burton S. Rosner. [1982] 2000. "Melodic Processes and the Perception of Music." In The Spheres of Music: A Gathering of Essays. Ed. Leonard B. Meyer. 157-85. Chicago: University of Chicago Press.

Millner, Fredrick Lewis. 1976. "The Operas of Johann Adolf Hasse.” Ph.D. diss., University of California, Berkeley.

Mirka, Danuta. 2014. "Topics and Meter." In The Oxford Handbook of Topic Theory. Ed. Danuta Mirka. 357-380. Oxford: Oxford University Press.

Neuwirth, Markus. 2015. "Fuggir la Cadenza, or The Art of Avoiding Cadential Closure: Physiognomy and Functions of
Deceptive Cadences in the Classical Repertoire." In What Is a Cadence? Theoretical and Analytical Perspectives on Cadences in the Classical Repertoire. Ed. Markus Neuwirth and Pieter Bergè. 117-56. Leuven: Leuven University Press.

Palmer, James K. 2017. "Humorous Script Oppositions in Classical Instrumental Music." Music Theory Online 23 (1).

Rabinovitch, Gilad. 2018. "Gjerdingen's Schemata Revisited." Journal of Music Theory 62 (1): 41-84.

Ratner, Leonard. 1970. "Ars combinatoria: Chance and Choice in Eighteenth-Century Music." In Studies in EighteenthCentury Music: A Tribute to Karl Geiringer on His Seventieth Birthday. Ed. H. C. Robbins Landon and Roger E. Chapman. 343-63. London: Allen and Unwin.

Rawbone, Trevor and Steven Jan. 2015. "A Grammatical Model of Butterfly Schemas in the Late-Classical Style." In Proceedings of the Ninth Triennial Conference of the European Society for the Cognitive Sciences of Music (ESCOM). Ed. Jane Ginsborg, Alexandra Lamont, M. Phillips, and Stephanie Bramley. 687-97. Manchester: Royal Northern College of Music.

Rice, John A. 2014. "The Heartz: A Galant Schema from Corelli to Mozart.” Music Theory Spectrum 36 (2): 315-32.

- 2015a. "Adding to the Galant Schematicon: The Lully.” Mozart-Jahrbuch 2014: 205-25.

- 2015b. "The Morte: A Galant Voice-Leading Schema as Emblem of Lament and Compositional Building Block." Eighteenth-Century Music 12 (2): 157-81. . 2017. "Climbing Monte Romanesca: EighteenthCentury Composers in Search of the Sublime." Unpublished Essay. https://www.academia.edu/32429345/ (accessed February 23 2018).

Rosch, Eleanor. 1978. "Principles of Categorization." In Cognition and Categorization. Ed. Eleanor Rosch and Barbara B. Lloyd. 27-48. Hillsdale, NJ: Lawrence Erlbaum Associates.

Rothstein, William. 1989. Phrase Rhythm in Tonal Music New York: Schirmer.

Samarotto, Frank. 2004. "Sublimating Sharp 4: An Exercise in Schenkerian Energetics." Music Theory Online 10 (3).

Sánchez-Kisielewska, Olga. 2016. "Interactions between Topics and Schemata: The Case of the Sacred Romanesca." Theory and Practice 41: 47-80.

Sanguinetti, Giorgio. 2012. The Art of Partimento: History, Theory, and Practice. Oxford: Oxford University Press.

Schank, Roger C. and Robert P. Abelson. 1977. Scripts, Plans, Goals and Understanding: An Inquiry into Human Knowledge Structures. Hillsdale, NJ: L. Erlbaum.

Schmalfeldt, Janet. 1992. "Cadential Processes: The Evaded Cadence and the 'One More Time' Technique." Journal of Musicological Research 12 (1-2): 1-52.

Sherrill, Paul. 2016. "The Metastasian Da Capo Aria: Moral Philosophy, Characteristic Actions, and Dialogic Form." Ph.D. diss., Indiana University.

Spitzer, Michael. 2008. "A Metaphoric Model of Sonata Form: Two Expositions by Mozart." In Communication in 
Eighteenth-Century Music. Ed. Danuta Mirka and Kofi Agawu. 189-229. Cambridge: Cambridge University Press.

Stendhal. 1839. The Life of Haydn, in a Series of Letters Written at Vienna, Followed by the Life of Mozart, with Observations on Metastasio, and on the Present State of Music in France and Italy. Boston: J. H. Wilkins and R. B. Carter.

Strohm, Reinhard. 1988. "Johann Adolph Hasses Oper Cleofide und ihre Vorgeschichte." In Johann Sebastian Bachs
Spätwerk und dessen Umfeld: Perspektiven und Probleme. Ed. Christoph Wolf. 170-76. Kassel: Bärenreiter.

van Tour, Peter. 2015. Counterpoint and Partimento: Methods of Teaching Composition in Late Eighteenth-Century Naples. Uppsala: Uppsala Universitet.

Weimer, Eric. 1984. Opera Seria and the Evolution of Classical Style: 1755-1772. Ann Arbor: UMI Research Press.

Zbikowski, Lawrence. 2017. Foundations of Musical Grammar. Oxford: Oxford University Press.
Music Theory Spectrum, Vol. 42, Issue 2, pp. 280-304, ISSN 0195-6167, electronic ISSN 1533-8339. (C) The Author(s) 2020. Published by Oxford University Press on behalf of The Society for Music Theory. All rights reserved. For permissions, please e-mail: journals.permissions@oup.com. DOI: $10.1093 / \mathrm{mts} / \mathrm{mtaa} 006$ 